\title{
Dysmaturation of Premature Brain: Importance, Cellular Mechanisms, and Potential Interventions
}

\section{Citation}

Volpe, JJ, Dysmaturation of Premature Brain: Importance, Cellular Mechanisms and Potential Interventions, Pediatric Neurology (2019), doi: https//doi.org/10.1016/ j.pediatrneurol.2019.02.016.

\section{Permanent link}

http://nrs.harvard.edu/urn-3:HUL.InstRepos:40508779

\section{Terms of Use}

This article was downloaded from Harvard University's DASH repository, and is made available under the terms and conditions applicable to Open Access Policy Articles, as set forth at http:// nrs.harvard.edu/urn-3:HUL.InstRepos:dash.current.terms-of-use\#OAP

\section{Share Your Story}

The Harvard community has made this article openly available.

Please share how this access benefits you. Submit a story.

Accessibility 
Dysmaturation of Premature Brain: Importance, Cellular Mechanisms

and Potential Interventions

\author{
Joseph J. Volpe, M.D..$^{a, b}$ \\ ${ }^{a}$ Department of Neurology, Harvard Medical School, Boston, MA \\ ${ }^{b}$ Department of Pediatric Newborn Medicine, Harvard Medical School, Boston, MA
}

Communications should be addressed to:

Joseph J. Volpe, M.D.

Department of Pediatric Newborn Medicine

Brigham and Women's Hospital

221 Longwood Avenue, Room 343C

Boston, MA 02115 USA

Joseph.volpe@childrens.harvard.edu

Tel: $617-525-4145$

Key words: prematurity; white matter injury; pre-oligodendrocytes; brain dysmaturation;

neurorestoration

Word count: 11,920 


\section{ABSTRACT}

Prematurity, especially very preterm birth ( $<32$ weeks' gestation), is common and associated with high rates of both survival and neurodevelopmental disability, especially apparent in cognitive spheres. The neuropathological substrate of this disability is now recognized to be related to a variety of dysmaturational disturbances of brain. These disturbances follow initial brain injury, particularly cerebral white matter injury, and involve many of the extraordinary array of developmental events active in cerebral white and gray matter structures during the premature period. This review delineates these developmental events and the dysmaturational disturbances that occur in premature infants. The cellular mechanisms involved in the genesis of the dysmaturation are emphasized, with particular focus on the preoligodendrocyte (pre-OL). A central role for the diffusely distributed activated microglia and reactive astrocytes in the dysmaturation is now apparent. Because these dysmaturational cellular mechanisms appear to occur over a relatively long time-window, interventions to prevent or ameliorate the dysmaturation, i.e., neurorestorative interventions, seem possible. Such interventions include pharmacological agents, especially erythropoietin, but also particular attention to such nutritional factors as quality and source of milk, breastfeeding, polyunsaturated fatty acids, iron and zinc. Recent studies also suggest a potent role in enhancing brain development for interventions directed at various experiential factors in the neonatal period and infancy, i.e., provision of optimal auditory and visual exposures, minimization of pain and stress, and a variety of other means of environmental behavioral enrichment. 


\section{INTRODUCTION}

Preterm birth ( $<37$ weeks' gestation) is an enormous public health problem worldwide. According to the WHO, approximately 15 million premature infants are born yearly and account for approximately 1 million deaths. ${ }^{1}$ The USA ranks sixth among countries with the greatest number of preterm births. According to the CDC, from 2014 to 2017 the preterm birth rate rose in the US to approximately $10 \%$. Of the approximately 4 million births in the USA, $1.4 \%$, or about 56,000 , are of very low birth weight $(<1500 \mathrm{gm}) .^{2}$ Survival rates vary markedly as a function of gestational age, but are at least $95 \%$ at 32 weeks' gestation, $90 \%$ at 28 weeks, and 60 $-65 \%$ at 24 weeks. ${ }^{3-5}$ The substantial survival rates, unfortunately, are accompanied by relatively high incidences of neurological disability, e.g., cerebral palsy in $5-10 \%$, other motor disturbances in $25-40 \%$, and cognitive, attentional, behavioral and socialization disturbances in $25-50 \% .^{6-16}$

The neuropathological substrate of this disability in preterm infants, especially those very preterm ( $<32$ weeks' gestation) and extremely preterm ( $<28$ weeks' gestation), consists of a combination of cerebral white matter injury (WMI) and especially, subsequent dysmaturational events in both white matter and neuro-axonal structures (see later). This combination of WMI and disturbances of gray matter structures has been termed the "encephalopathy of prematurity". ${ }^{17}$ In the initial review describing this encephalopathy, a particular emphasis was placed on the initial injury. ${ }^{17}$ Subsequent work now suggests that although WMI is an important and likely initiating event, multiple subsequent dysmaturational events are most critical in determining outcomes (see later). Moreover, because these dysmaturational events evolve over a very prolonged period (many months), a relatively long-time window exists for interventions to 
prevent, counteract or ameliorate the dysmaturation, i.e., neurorestorative interventions (see later).

In the following, I will review the multiple maturational events occurring in infant brain during the premature period; the dysmaturational events observed in premature infants, including the importance of the initiating cerebral WMI; the dysmaturational events that may occur without WMI; and potential neuroprotective and neurorestorative interventions.

\section{BRAIN MATURATION DURING THE PREMATURE PERIOD}

The brain dysmaturation that occurs in premature infants (see later) involves the multiple active developmental events occurring in human cerebrum during the period of 20 - 40 weeks of gestation and beyond. The rapidity and complexity of these cellular events underlie, to a considerable degree, their vulnerability to perturbations. The principal components involved include the oligodendroglial (OL) lineage, especially the pre-oligodendrocyte (pre-OL), cerebral white matter axons, subplate neurons, cerebral cortex, thalamus and basal ganglia (Fig. 1). Additionally, microglia and astrocytes, especially in white matter, are involved importantly in both normal development and dysmaturation of these principal components. The major developmental events during this period have been summarized in detail elsewhere. ${ }^{18,19} \mathrm{~A}$ brief review of the temporal aspects of these events is appropriate here (Table 1).

\section{Pre-OL as a Principal Cellular Target}

Pre-OLs are the principal cellular target in WMI of premature infants. ${ }^{20-22}$ These cells are generated from OL progenitors and are the principal phase of the OL lineage during the premature period (Table 1, Fig. 2). Pre-OLs account for $90 \%$ of the lineage during the peak period of WMI in premature infants. Even at term, pre-OLs account for $50 \%$ of the lineage in 
cerebral white matter, while approximately $50 \%$ of the lineage are the more differentiated "immature" OLs. ${ }^{23}$ Mature, myelin-producing OLs do not develop in human cerebral white matter to an appreciable degree until post-term. The pre-OL begins ensheathment of white matter axons at approximately 30 weeks' gestation (Fig. 3) ${ }^{24}$ This process is critical for axonal differentiation ${ }^{25-35}$ and, as a consequence, axonal function. The latter is the critical driving force for cerebral cortical development (see later), which evolves rapidly as an activity-dependent process during the third trimester of gestation.

The pre-OL is a highly vulnerable cell, with particular susceptibility to such insults as hypoxia, ischemia, inflammation, which lead to death via excitotoxic and free radical mediated mechanisms. ${ }^{20}$ The particular molecular characteristics that underlie this pre-OL vulnerability have been reviewed elsewhere. ${ }^{22}$ Suffice it to say here, many experimental studies of acute preOL death produced by hypoxia, ischemia and inflammation have shown protective benefit for such agents as anti-excitotoxic, anti-inflammatory and anti-oxidant compounds (see later). Notably, however, as will be discussed later, in the premature infant with WMI, pre-OLs are replenished in the subacute period but fail to differentiate over the ensuing weeks/months to later phases of the OL lineage. As a result, hypomyelination is a hallmark of the disease.

\section{Axons}

Axonal development is remarkably active in the cerebrum during the premature period (and the early postnatal period) (Table 1 ) ${ }^{36}$ Utilizing immunostaining with GAP-43, a protein expressed on growing axons, Haynes et al., ${ }^{36}$ showed marked expression in cerebral white matter to at least 37 weeks' gestation. Growing white matter axons reach approximately the subplate region at 20 weeks, the deep layers of the cortical plate at 27 weeks, and the entire cortex by 37 weeks. (Fig 4). Axonal growth occurs primarily within the cortex after 37 weeks and into the 
first year of life. Based on work by Kostovic and coworkers, ${ }^{3740}$ the likely anatomic correlates of this progression in cerebral white matter during the premature period are at 20 weeks, growth of axons from thalamus to subplate neurons, and at 27 weeks, from subplate neurons to cerebral cortex (Table 1). Also, at 27 weeks commissural and cortico-cortical cerebral white matter axons are actively growing, especially in the posterior periventricular regions, a so-called "crossroads" area. The increase in cerebral cortical expression of GAP-43 at 37 weeks may reflect a sum of continued cortical penetration from the subplate of thalamic ascending fibers and of commissural and cortico-cortical fibers (Fig. 4). Thus, it is apparent that the premature period is one of extraordinarily rapid axonal development, especially in cerebral white matter. Axons during this rapid growth period are exquisitely vulnerable to multiple insults (see later).

\section{Cerebral Cortex-Dendritic Development, Synaptogenesis}

The cerebral cortex undergoes dramatic changes during the premature period. These events include attainment of proper alignment, orientation and layering of cortical neurons (six layers apparent by 30 gestational weeks), arrival of late migrating GABAergic neurons (principally to upper cortical layers), elaboration of dendritic and axonal ramifications (neurite outgrowth), onset of synaptogenesis, and a marked increase in cortical surface area with gyral development (Table 1$)^{18}$

Neurite outgrowth, and particularly dendritic development, is most relevant in this context. ${ }^{41-44}$ Dendritic development is especially rapid in the third trimester (Fig 5) and is correlated with the development of cortical activity (Table 1). ${ }^{18}$ Importantly, in this context the progress of dendritic development depends on the establishment of afferent input from cerebral white matter and presumably then synaptic activity. ${ }^{42,45-56}$ Thus, axonal input from subplate neurons and then from thalamic, commissural and cortico-cortical fibers are the principal driving 
forces underlying cortical dendritic development. ${ }^{56}$ The importance of synaptogenesis in mediation of these effects of axonal input on cortical development has been emphasized in several studies. ${ }^{57}$ (See ref 57 for review.) In a seminal study, Sarnat and coworkers studied synaptic development in human cerebral cortex from 6 to 41 weeks' gestational age with the immunomarker synaptophysin, which identified maturation of synaptic vesicles in axonal terminals. Thalamocortical axons exhibited intense staining in frontal cortex at approximately 26 weeks' gestation, and diffuse and uniformly strong staining was apparent throughout the cortex from 34 weeks onward. ${ }^{58}$ The findings integrate closely with measures of axonal development in the last trimester of gestation and with previous delineations of EEG maturation in premature infants. Functional synaptic activity via the axonal input to cortex is mediated principally through excitatory amino acid receptors, both the excitatory $\mathrm{Ca}^{++}$-permeable NMDA and GluR2deficient AMPA receptors, which exhibit exuberant expression in developing human cortex during this period..$^{59,60}$ This role of functional activity has implications for the effects of a variety of environmental stimuli on cortical development in the premature infant, and for potential neurorestorative roles for such stimuli in the context of brain injury and dysmaturation (see later).

\section{Subplate Neurons}

This important transient population of neurons is well-established in subcortical white matter by 20 weeks' gestation. ${ }^{37-40,61}$ During the important period of $24-32$ weeks (the peak period for the occurrence of cerebral WMI) the subplate reaches maximum size (several times thicker than the cortical plate at 27-30 weeks) (Fig. 1, Table 1). These neurons elaborate a dendritic arbor with spines, receive synaptic inputs from ascending afferents from thalamus and distant cortical sites, ${ }^{18}$ and extend axon collaterals to the overlying cerebral cortex and to other 
cortical and subcortical sites (thalamus, other cortical regions, corpus callosum). The crucial organizational functions of these neurons include provision of a transient synaptic site for ascending afferents from thalamus and other cortical sites, i.e., these "waiting" afferents cannot synapse yet in cortex because their neuronal targets have not yet differentiated. These afferents would undergo degeneration if they did not have the subplate neurons as transient targets. Moreover, the subplate neurons extend axons to cortex to promote cortical differentiation and to guide the afferent axons to cortex when sufficient cortical differentiation has occurred. Subplate axon collaterals also descend to pioneer or guide the initial axonal projections from cerebral cortex toward subcortical sites (e.g., thalamus, corpus callosum, other cortical sites). The subplate neuronal layer gradually decreases after 36 - 40 weeks' gestation.

\section{Late Migrating GABAergic Neurons}

Particularly characteristic of human cerebral cortical development is the relatively late generation of GABAergic neurons from the dorsal telencephalic subventricular zone and from the ventral ganglionic eminence (Fig. 6) ${ }^{61-65}$ The origin of these late generated neurons is approximately $65 \%$ from the dorsal subventricular zone and $35 \%$ from the ventral ganglionic eminence. A substantial proportion of the ultimate population of GABAergic cortical neurons migrate through the cerebral white matter to cortex in the third trimester. This migration peaks around term and then declines within the first 6 postnatal months. ${ }^{66}$

\section{Microglia, Astrocytes}

Microglia and astrocytes are key players in the development of the white and gray matter structures just described. These glial elements also play a major causal role in the dysmaturational events that occur with cerebral WMI. Emphasis in this section is on the roles of 
microglia and astrocytes in normal development. Their role in dysmaturation is discussed later in the section on neuropathology.

\section{Microglia}

Microglia play important roles in such aspects of brain development as axonal development, OL differentiation-myelination, vascularization, synaptogenesis, synaptic pruning, and neural circuit formation. ${ }^{67-76}$ The roles in OL development involve microglial proteins that stimulate pre-OL proliferation, enhance pre-OL survival and provide iron for OL differentiation, and secreted cytokines that enhance differentiation. ${ }^{75}$ These cells also are the principal neuroimmune cells involved in neuroinflammatory responses. As part of the neuroinflammatory responses microglia can be destructive to cellular elements, such as pre-OLs, principally by generating free radicals, secreting injurious cytokines and enhancing excitotoxicity (see later). ${ }^{73,}$ ${ }^{77-85}$. Microglia have been characterized generally as pro-inflammatory (activated) (MI) or antiinflammatory (M2). However, this bimodal characterization appears now to be too simplistic. Thus, a recent landmark study in the developing mouse, utilizing molecular characterization methods, identified at least nine distinct microglial subpopulations with unique molecular signatures that changed over the course of development and exhibited marked spatial differences. ${ }^{76}$ One distinct population was highly concentrated in axon tracts of the premyelinated brain. The molecular signatures of the microglial subpopulations in early development identified pathways associated with cell metabolism, growth, motility and proliferation, among others. Studies in developing human brain will be of great interest.

Microglia become prominent in the human forebrain at 16-22 weeks of gestation, migrate progressively through the white matter from $20-35$ weeks, and then to cerebral cortex. ${ }^{69,80,86,87}$ The critical point is that the cerebral white matter of the human premature infant is heavily 
populated with microglia during a period when various maturational events are occurring and when a variety of pro-inflammatory insults can lead to "activation" to destructive microglial phenotypes and WMI (see later). Moreover, because of the important role of microglial subpopulations in such important developmental events as OL development, axonal guidance, synaptogenesis, sculpting of neural networks, cerebral connectivity, diversion of these normal cells to microglial phenotypes with primarily pro-inflammatory functions could contribute to disturbances in these maturational events observed in the premature brain. ${ }^{72,73}$

\section{Astrocytes}

The last half of human gestation also is a crucial time in astrocyte formation in the cerebrum. ${ }^{18}$ Fibrous astrocytes (generated from radial glial fibers) increasingly populate cerebral white matter. During development astrocytes are important in axonal guidance, angiogenesis, formation of the blood-brain barrier, synaptogenesis, neuronal survival and axonal and synaptic pruning. ${ }^{72}$ The molecular characteristics of astrocytes involved in facilitation of these events underlie such functions as expression of extracellular matrix proteins and axonal guidance molecules, secretion of angiogenic factors, secretion of synaptogenesis molecules, clearance of extracellular glutamate, and secretion of various neurotrophic molecules. As will be discussed later, in the context of various brain insults (e.g., inflammation, hypoxia-ischemia), astrocytes can become "reactive" and exhibit a variety of metabolic changes that are deleterious to other white matter components, including pre-OLs.

\section{DYSMATURATION IN PREMATURE BRAIN}

\section{Overview}


The principal manifestations of dysmaturation in premature brain have been elucidated by advanced MRI techniques in living infants (Table 2). Briefly, the abnormalities have been: by volumetric MRI, diminished regional volumes, especially of cerebral cortex, white matter, thalamus and basal ganglia; by diffusion-based imaging, in cerebral white matter, decreased fractional anisotropy (FA) with relatively greater involvement of radial diffusivity (consistent with impairment of pre-OL ensheathment of axons), and in cerebral cortex, blunting of the normal decline in FA (consistent with impaired dendritic development); by surface-based MRI measures, decreased cerebral cortical surface area and cortical folding/gyrification; and by functional MRI, impaired development of measures of connectivity, including especially thalamocortical connectivity. The abnormalities have been elucidated most commonly at term equivalent age, but generally persist, or may increase later in infancy, childhood, adolescence or adulthood. ${ }^{88-93}$ The most common accompaniment by MRI has been cerebral WMI (see later). The dysmaturational events, in general, appear to be secondary to WMI (see later discussion of mechanisms). The constellation of WMI and the accompanying disturbances of neuronal/axonal structures is generally referred to as the encephalopathy of prematurity, ${ }^{17}$ However, recent work suggests that some of the dysmaturational events documented in premature infants are not clearly related to WMI and perhaps are primary disturbances (see later). The emphasis in the following section is on the relation of cerebral WMI and dysmaturational events. Brief consideration of potentially primary dysmaturational events, perhaps independent of WMI, will then be presented.

\section{Cerebral White Matter Injury — A Spectrum}

\section{Neuropathology}

Cerebral WMI encompasses a spectrum of neuropathology that ranges from overt periventricular leukomalacia (PVL) to diffuse white matter gliosis (DWMG) (without focal 
necroses) (Fig.7A-C). The two fundamental characteristics of PVL are focal necroses with loss of all cellular elements in periventricular white matter and a more diffuse lesion in cerebral white matter, consisting initially of death of early differentiating pre-OLs, accompanied by vigorous and persistent astrogliosis and microgliosis (Fig 8). ${ }^{94-102}$ The focal necroses are essentially infarcts. Temporally, in the more diffuse lesion the pre-OL disturbance consists acutely of cell death, followed subacutely and chronically initially by proliferation of pre-OLs but then critically, a failure of maturation. ${ }^{103-108}$ As noted earlier, this pre-OL dysmaturation underlies the subsequent hypomyelination, a unifying feature of PVL. The mildest form of WMI, i.e., diffuse white matter gliosis (DWMG) without focal necroses, now is the most common form of WMI in premature infants and is also accompanied by the pre-OL dysmaturation. ${ }^{100-102}$

The relative distribution of the spectrum of cerebral WMI in the modern era has been delineated best by neuropathological studies. The two largest, most recent series demonstrate that compared with earlier studies, the areas of focal necrosis are smaller and, indeed, most cases have few or none. ${ }^{100,101}$ In the series of Pierson et al. (n=41), true PVL, i.e., with focal necroses, occurred in 17 (42\%). Importantly, nearly all of these lesions were less than $1 \mathrm{~mm}$ in size. In an additional 17 (42\%) only DWMG without focal necroses was observed. (Only 7 of the 41 brains were free of white matter abnormality.) Critically, Busser and coworkers observed in association with DWMG the sequelae of pre-OL death, i.e., the excess of pre-OLs and failure of pre-OL maturation. ${ }^{101}$ Thus, the full spectrum of cerebral WMI can be illustrated as shown in Fig. 7A-C.

\section{Pathogenesis}

The pathogenesis of the focal necroses characteristic of PVL relates primarily to decreases in cerebral blood flow, related to a variety of perinatal/neonatal events, and the presence in the periventricular area of vascular border zones and end zones. ${ }^{20,22}$ The diffuse 
abnormality, DWMG, relates in considerable part to similar, albeit less severe clinical events (see later).

In the diffuse lesion the pathogenesis of the acute pre-OL injury/death likely relates in part to the acute insults, noted above, as well as accompanying disturbances that may predispose the pre-OL to injury (e.g., intrauterine growth retardation, systemic infection, impaired nutrition, etc.) (see later). The stimulus for the subsequent proliferative response of $\mathrm{OL}$ progenitors to produce abundant pre-OLs remains unclear. The pathogenesis of the subacute and chronic failure of maturation of these newly generated pre-OLs appears to relate to deleterious effects of the abundant activated microglia and reactive astrocytes characteristic of the diffuse lesion. These components likely are involved in other dysmaturational events relating to axonal and neuronal structures, as described next.

\section{Deleterious Roles of Microglia and Reactive Astrocytes. The pro-inflammatory}

microglia may impair pre-OL maturation by release of reactive oxygen/nitrogen species or cytokines (e.g., TNF- $\alpha$, ILI- $\beta$ ) that then act on pre-OLs. ${ }^{20}$ Recent studies of multiple sclerosis lesions have identified an inflammatory subpopulation of microglia that specifically targets myelin. ${ }^{76}$ Whether such subpopulations are involved in pre-OL dysmaturation is unknown, but it is noteworthy that a large population of potentially activatable microglia are present in normal developing white matter during the premature period (see earlier). Additionally, proinflammatory microglia have been shown recently to induce formation of neurotoxic reactive astrocytes. ${ }^{109,110}$ As discussed next, such astrocytes are important in the pre-OL maturational failure. Finally, the shift in microglial phenotype from an anti-inflammatory to a proinflammatory, activated phenotype diverts the critical roles of "normal" microglia in OL development described earlier. 
The abundant "reactive" astrocytes (A1) in DWMG also likely play critical roles in the failure of pre-OL maturation. ${ }^{108-111}$ The best established mechanism in the context of WMI is based on seminal work by Back and coworkers. ${ }^{101,108,112}$ The likely sequence involves the generation by reactive astrocytes of high molecular weight forms of hyaluronic acid. Astrocyteassociated extracellular matrix (ECM) is also involved in this generation. ECM also is a key source of hyaluronidases, which convert the high molecular weight forms of hyaluronic acid to lower molecular weight forms. The latter lead to failure of pre-OL maturation, probably by activating TLR-2 receptors on pre-OLs. ${ }^{113}$ The particular role of hyaluronan is supported by the observation that pharmacological inhibition of hyaluronidases promotes pre-OL maturation and myelination (see later). Other products of reactive astrocytes may also be involved in the pre-OL dysmaturation. Thus, in human WMI reactive astrocytes express large amounts of interferon- $\gamma$, and pre-OLs express the interferon- $\gamma$ receptor, ${ }^{114}$ activation of which inhibits pre-OL differentiation. ${ }^{20}$ Other products of astrocytes may contribute to the inhibition of pre-OL differentiation, e.g., bone morphogenetic proteins, Notch ligand Jagged 1, but data on human preterm WMI are not yet available. ${ }^{108}$ Finally, as noted for activated microglia, the shift in astrocyte phenotype from normal fibrous astrocytes to the toxic reactive phenotype also diverts the critical roles of astrocytes in development of OLs (see earlier).

In view of the apparent critical roles of activated microglia and reactive astrocytes in disturbing pre-OL development (and likely also, aspects of axonal development), the question of the duration of DWMG in cerebral WMI of the premature infant becomes critical. Thus, available evidence by MRI in vivo suggests that dysmaturation continues for many months and likely longer. Not unexpectedly, neuropathological data in human infants concerning duration of DWMG are somewhat scanty. However, available information suggests that DWMG is present 
for at least many months after the premature period and likely longer. ${ }^{98,100,103,115}$ There is precedent for microglia to be chronically activated in human neuropathology, e.g., after traumatic brain injury. ${ }^{116}$ In the latter setting, these cells are considered important in subsequent degeneration of axons and neurons years later and to play a role in the enhanced incidence of degenerative disorders, such as Alzheimer's and Parkinson's disease.

\section{Identification In Vivo}

Neuroradiological identification of the cerebral WMI spectrum in vivo is made best by MRI but is not entirely satisfactory. Thus, the most severe end of the WMI spectrum, i.e., severe WMI, with large areas of necrosis and apparent cystic change, are readily identified as such (Fig 7D). However, such lesions are observed on MRI (and by neuropathology) in less than 5\% of infants in modern neonatal intensive care facilities. ${ }^{117,118}$. More common are small areas of necrosis $(>1 \mathrm{~mm})$ in periventricular and central cerebral white matter, seen at term equivalent age as (noncystic) punctate white matter lesions (PWMLs) in 15-25\%, i.e., moderate WMI (Fig 7E). ${ }^{119-122}$ Notably, this incidence of noncystic PVL (PWMLs) is appreciably higher if scans are performed early in the neonatal period - presumably the gliotic scars contract sufficiently to become invisible to MRI by term equivalent age. The least severe end of the WMI spectrum, i.e., mild WMI, is likely a heterogeneous group. Thus, the large majority of focal necroses observed postmortem are less than $1 \mathrm{~mm}$ in size. ${ }^{100,101}$ and likely below the resolution of most conventional MRI scanners. Additionally, the MRI correlate of the very common DWMG, without focal necroses, also is unknown. Importantly, as with the diffuse gliotic component of overt PVL, DWMG alone appears to lead to pre-OL death and subsequent dysmaturation, ${ }^{101}$ and thus may be very important clinically. The frequent isolated finding of diffuse signal abnormality in cerebral white matter (Fig. 7F) may be the MRI correlate of mild WMI, although both the 
reproducibility of this imaging finding and the relation to outcome remain unclear. ${ }^{102}$ The few excellent studies that identify WMI without detectable focal necroses by the presence of diminished FA on diffusion-based MRI (see later) may be the best in vivo correlate of the admixture of the WMI spectrum that includes the two large groups of (1) focal necroses too small for identification (with DWMG), and (2) DWMG without any focal necroses, the two forms that we refer to as mild WMI..

\section{Clinical Importance}

The clinical importance of the cerebral WMI spectrum relates to the motor and cognitive deficits associated with the lesion and the subsequent dysmaturation. The clinical phenomena associated with moderate and severe WMI have been described in detail

elsewhere. ${ }^{118}$ Identification of the neurodevelopmental sequelae of mild WMI is hindered by the difficulty in identifying the lesion by conventional MRI, as used in most large-scale studies. Large-scale MRI studies of premature infants show, as expected, worsening clinical outcomes as a function of severity of WMI. However, it is noteworthy that infants with either no or "mild" abnormality in cerebral white matter by conventional MRI still exhibit neurological disability subsequently. Although cognitive scales utilized among studies vary, cognitive scores for infants ( $<28-30$ weeks' gestation) with no or "mild" WMI are approximately $85-93 .{ }^{121,123-125}$ In a particularly well-characterized study of 480 extremely preterm infants ( $<28$ weeks' gestation), $20 \%$ of infants with no apparent WMI by conventional MRI had cognitive scores $<85$. $^{124}$ The possibility that neuro-axonal dysmaturation with mild WMI (see Mechanisms later) is important in determination of these outcomes is suggested by follow-up studies that included assessment of gray matter abnormalities (as well as WMI). ${ }^{126}$ As will be discussed later, studies that assess 


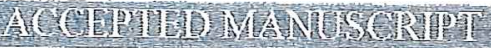

WMI by highly sensitive diffusion MRI measures show a clear association between mild WMI, dysmaturation and subsequent cognitive disturbances.

\section{Mechanisms of Dysmaturation with Cerebral White Matter Injury}

The mechanisms of the dysmaturational features identified by MRI in premature brains (Table 2), especially in the context of WMI, are likely multiple. The prevailing theme is a sequence whereby the initial insult (hypoxia, ischemia, inflammation, infection, etc.) leads to primary cellular injury/death, which in turn results in subsequent replenishment of pre-OLs but secondary dysmaturation. The cellular elements injured likely depend on the severity of the WMI. Thus, in moderate-severe WMI (Fig 7A,B), all the rapidly developing cellular elements, as outlined next, appear to be injured, whereas in mild WMI (Fig 7C), the pre-OL may be the principal or only cellular element undergoing primary injury.

\section{Dysmaturation with Moderate-Severe White Matter Injury}

Pre-OL Injury. Primary injury/death to the pre-OL, which is exquisitely vulnerable to hypoxic-ischemic, inflammatory or related insults, is a consistent early feature of all forms of WMI. ${ }^{21,108,127}$ Cell death (or irreversible process loss) or both have been documented acutely. ${ }^{21 \text {, }}$ 103, 105, 108, 127 Subsequently, over the ensuing weeks replenishment of the pre-OL pool occurs but subsequent maturation to mature, myelin-producing OLs fails. The important role of reactive astrocytes and activated microglia in this dysmaturation was described earlier. The result of this pre-OL dysmaturation is hypomyelination (Fig. 9A). Additionally, however, pre-OL dysmaturation likely leads to failure of pre-OL ensheathment of axons, and as a consequence, impaired development, i.e., dysmaturation, of axons. The important trophic role of pre-OLs for axonal development, survival and function was noted earlier. Indeed, this process is likely crucial 
for the exuberant axonal growth in cerebral white matter illustrated earlier (Fig 4) and the activity-dependent development of cerebral cortex (Fig. 5).The consequences of the axonal disturbance would be diminished volumes of cerebral cortex and thalamus/basal ganglia, secondary to retrograde and anterograde (trans-synaptic) effects, i.e., involving projection fibers to and from cortex, thalamus and basal ganglia, i.e., thalamocortical, corticospinal, corticostriatal, and commissural and association fibers to and from cortex, i.e., cortico-cortical). (Fig. 9A).

Axonal Injury. Primary injury to the rapidly developing, vulnerable, premyelinating axons in cerebral white matter could be a primary event with WMI (Fig. 9B). Although axonal injury is shown readily in the areas of focal necrosis, a more widespread degeneration of axons detected by the apoptotic marker, fractin, also has been identified. ${ }^{128}$ This finding is consistent with related experimental observations concerning the vulnerability of developing axons, ${ }^{129-133}$ The dysmaturational events subsequent to axonal injury (Fig 9B) by anterograde and retrograde effects would result in the impairments of cortical and thalamic development and related abnormalities detected by MRI (see Table 2). An impairment of pre-OL maturation would result from the loss of trophic axonal signals, with the ultimate consequence, hypomyelination. A contributory role for deleterious effects of activated microglia and reactive astrocytes (see earlier) also seems likely. Moreover, because of the role of both these glial types in normal axonal development, diversion to activated/reactive phenotypes may further impair axonal development.

Thalamic Injury. Primary injury to thalamus is suggested by a neuropathological study of human infants with moderate to severe WMI and thalamic abnormalities (neuronal loss, gliosis, axonal degeneration) detected in approximately $60 \% .{ }^{100,134} \mathrm{~A}$ particular vulnerability of 


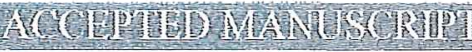

thalamus has also been shown in an experimental model. ${ }^{135,136}$ Primary injury to thalamus could lead to degeneration of axons originating in and terminating in thalamus and, as a consequence, to pre-OL dysmaturation and hypomyelination (Fig. 9C).

Subplate Neuronal Injury. Primary injury to subplate neurons would be expected to have major secondary dysmaturational effects on thalamus by retrograde degenerative effects on ascending thalamic axons ("waiting afferents"), as well as on cerebral cortex by anterograde effects via loss of subplate neuronal axons to cortex and on descending cortical axonal projections by loss of guidance from subplate axonal collaterals (Fig. 9D). Considerable experimental data support these contentions. ${ }^{37,137-144}$ With axonal degeneration, subsequent disturbances in pre-OL development would be expected (Fig. 9D). Although data are not entirely consistent, experimental studies suggest that subplate neurons are particularly vulnerable to hypoxia-ischemia. ${ }^{145}$ Two reports suggest a loss of subplate neurons in premature infants with moderate-severe white matter injury. ${ }^{146,147}$

Late Migrating GABAergic Neurons. Primary injury to late migrating GABAergic neurons seems possible because the migratory path of these late generated cells is from the dorsal subventricular zone through cerebral white matter to the cerebral cortex (Fig. 6). Two neuropathological studies of moderate-severe WMI show a deficit in central white matter neurons consistent with late migrating GABAergic neurons. ${ }^{146,147}$ The result of a disturbance in these neurons would be a deficit in cerebral cortical neurons, especially the upper cortical layers (Fig 9E). The MRI result would be diminished cerebral cortical volume, surface area, gyrification and connectivity, as noted in advanced MRI studies (Table 2).

Conclusions. Thus, in moderate to severe WMI, i.e., identified by neonatal MRI by PWMLs (relatively common) or by cystic lesions (rare), several potential sequences of primary 
injury leading to dysmaturation and the developmental impairments detected by advanced MRI techniques seem likely. Although pre-OL death and subsequent replenishment of pre-OLs which then fail to mature appear most consistent (Fig. 9A), the other sequences depicted in Fig. 9 may also occur to varying degrees, dependent in part on such factors as the gestational age of the infant, the nature, severity and timing of the initiating insult(s), and the presence of other potentiating factors, e.g., intrauterine adversity, postnatal infection, undernutrition, etc.

\section{Dysmaturation with Mild White Matter Injury}

Mild WMI, as discussed earlier is characterized by focal necrotic lesions less than approximately $1 \mathrm{~mm}$ in size, and thus undetectable by conventional MRI, or DWMG without focal necroses. (Fig.7C) The dysmaturational features apparent subsequently in vivo by advanced MRI are similar in many respects to those described earlier for moderate and severe WMI (Table 2) but are less pronounced. ${ }^{118,148-155}$ Thus, a series of careful studies of premature infants without major WMI and utilizing diffusion-based MRI determinations of FA and related measures in cerebral white matter as a means to detect mild WMI, not readily apparent on conventional MRI, show at term-equivalent age disturbances in volumetric development of cerebral cortex, cerebral white matter, thalamus, basal ganglia, cortical folding, cortical and white matter microstructure, and thalamocortical connectivity. ${ }^{148-153,155-157}$ In a particularly large, recent series $(n=491)$, Barnett et al. identified lower FA in cerebral white matter with particularly high radial (vs. axial) diffusion (RD). ${ }^{155}$ The high RD is consistent with an impairment of pre-OL ensheathment. ${ }^{118,158}$ The findings suggest that impaired pre-OL maturation is the critical finding in mild cerebral WMI. The lower FA values were independently associated with increased number of days on ventilation, perhaps consistent with chronic hypoxia or related insults and with fetal growth restriction. The latter has been shown to 
be associated with a degree of hypoxia and in experimental studies to lead to delayed OL maturation ${ }^{155,159}$ - recall that the pre-OL is exquisitely vulnerable to hypoxic and related insults (see earlier). The white matter findings also related to prolonged parenteral nutrition and suggest that impaired nutrition may lead to impaired pre-OL development (see later). Importantly, the abnormal FA values in the large study of Barnett et al. were associated with impaired neurodevelopmental performance at 20 months of age. ${ }^{155}$

As noted earlier, two major neuropathological series indicate that mild WMI, as defined here, is the dominant form of cerebral WMI currently. ${ }^{100,101}$ As noted earlier, detection of this milder but prevalent form of WMI cannot be made consistently by conventional MRI. The recent work just described with diffusion-based MRI indicates promise for detection in vivo.

Although the mechanisms for dysmaturation with mild WMI may overlap with those just described for moderate to severe WMI, major differences are likely. Thus, with mild WMI clear evidence for primary injury to components other than the pre-OL is lacking. It is most likely that with mild WMI the deleterious effects of the abundant activated microglia and reactive astrocytes are the dominant mediators of dysmaturation, especially to the pre-OL, and perhaps also to axons.

Pre-OL Injury. Primary injury/death to the pre-OL with subsequent replenishment of pre-OLs but failure of maturation, as described for moderate-severe WMI (see earlier), may be the major mechanism for the widespread dysmaturation just described. The important role of activated microglia and reactive astrocytes was discussed earlier concerning moderate to severe WMI. The scenario to widespread dysmaturation, thus, would be similar to that described for moderate-severe WMI (Fig. 9A). 
Axonal Injury. Although evidence for primary injury to axons in mild WMI is lacking, the deleterious effects of the abundant activated microglia and reactive astrocytes may disturb axonal development, separate from any effects on pre-OLs. Additionally, as noted earlier, during normal development these glia are critical for axonal guidance and growth, and phenotypic diversion to activated/reactive cells could lead to dysmaturation. Thus, a scenario similar to that depicted in Fig. 9B seems possible.

Thalamic, Subplate, Late Migrating GABAergic Neuron Injury. The scenarios described earlier for primary injury to these neural structures leading to dysmaturational gray matter disturbances in the setting of moderate-severe WMI (Fig 9C-E) cannot be ruled out in mild WMI but do not seem highly likely. For example, in the careful neuropathological study of Pierson et al., ${ }^{100}$, in the 17 infants with DWMG (and no focal necroses), neuronal loss in cortex, thalamus, and basal ganglia was observed in none.

Conclusions. The dysmaturational disturbances of white matter and gray matter structures apparent by advanced MRI methods in infants with mild WMI do not appear to be related to widespread injury. Pre-OL injury and dysmaturation do seem apparent, and thus the possibility of the multiple secondary developmental disturbances of gray and white matter structures described earlier (Fig. 9A) is real. The abundant reactive astrocytes and activated microglia in cerebral white matter, i.e., DWMG, also are likely important in the pre-OL injury/dysmaturation. Additionally, axonal injury and dysmaturation also are a potential consequence of the deleterious actions of these two glial types (Fig. 9B).

\section{Primary Dysmaturation of Gray Matter Structures}


The possibility that the gray matter structures shown to exhibit secondary impaired development with the encephalopathy of prematurity, as outlined in the preceding, may exhibit primary dysmaturation is suggested by recent clinical and experimental studies. If primary dysmaturation does occur, the approaches to neuroprotection and neurorestoration (see later) could be quite different than those directed at secondary dysmaturation in the context of cerebral WMI.

\section{Clinical Data}

Primary dysmaturation of cerebral cortex, in the absence of evidence for WMI, is suggested by a study of 95 premature infants studied by MRI at two time points in the neonatal period (32 and 40 weeks post-conception). ${ }^{160}$ The principal finding was evidence for delayed microstructural development of cerebral cortical gray matter at multiple sites. Diffusion-based measurements showed delayed microstructural development in cerebral cortex, but not cerebral white matter, in association with impaired somatic growth. The expected normal developmental decline in FA in cortex was blunted, whereas the expected increase in FA in white matter was not. Thus, no evidence for WMI or impaired white matter development could be identified. As described earlier, ${ }^{18,161} \mathrm{FA}$ decreases in cortex principally with dendritic development. In the study of Vinall et al. ${ }^{160}$ radial diffusion and not axial diffusion in cortex was particularly affected, again most consistent with impaired dendritic development. The association with impaired somatic growth raises the possibility that undernutrition is particularly involved, although detailed data re: nutrition, caloric intake, feeding were not available. However, it is noteworthy that several studies of premature newborns with intrauterine growth retardation also show a particular involvement of cerebral cortical development, including reduced cortical volume, reduced cortical surface area and impaired gyrification. ${ }^{162-166}$ However, other studies of 
such infants have shown abnormalities in microstructural development of white matter. ${ }^{155,167}$ Nonetheless, on balance, it does appear that disturbances in growth, perhaps secondary to undernutrition, either in the premature infant postnatally or in utero may have a primary dysmaturational effect on cerebral cortex. More data clearly are needed.

\section{Experimental Data}

Three recent studies in a well-characterized preterm large animal (fetal sheep) model of cerebral ischemia raise the possibility of primary dysmaturation of cerebral cortex, subplate neurons and caudate neurons. ${ }^{168-170}$ Thus, utilizing elegant neurobiological methods, Back and coworkers have shown disturbances in cortex, in dendritic development and synapse formation; in subplate neurons, in dendritic arborization and synaptic activity; and in caudate, in dendritic arborization, synaptogenesis and synaptic activity. ${ }^{168-170}$ These findings were apparent four weeks after the hypoxic-ischemic insult, but not after two weeks. ${ }^{168}$ Because the basic experimental paradigm was designed originally to replicate cerebral WMI of the premature infant, these examples of neuronal dysmaturation were accompanied by pre-OL degeneration and dysmaturation and diffuse gliosis with reactive astrocytes and reactive microglia. A reasonable question is whether the 4-week period required for the evolution of the cortical, subplate or caudate neuronal dysmaturation is necessary because the dysmaturation is secondary to the preOL degeneration and dysmaturation as described earlier (Fig 9A). In the absence of a definitive answer to this question, the possibility that the hypoxic-ischemic insult leads primarily and directly to the neuronal dysmaturations is real. Coupled with the clinical study described earlier, the latter possibility demands further research.

\section{Conclusions}


The clinical studies of premature infants with impaired somatic growth and of those with intrauterine growth retardation raise the possibility that cerebral cortical development may be affected directly, i.e., primarily, perhaps by nutritional factors. In view of the rapid development of cortex during the premature period and therefore its likely vulnerability to neonatal insults, such a possibility seems reasonable. Experimental data also raise the possibility of a primary dysmaturational effect for hypoxia-ischemia on cortical, subplate and caudate neurons. However, as discussed, the available data do not rule out a primary effect on pre-OLs with secondary neuronal dysmaturation.

\section{NEUROPROTECTIVE AND NEURORESTORATIVE INTERVENTIONS}

Because the pervasive theme in this review is that pre-OL death leads to subsequent dysmaturation of both white and gray matter structures, interventions are best considered (1) as preventative of the initial death (i.e., neuroprotection) or (2) as amelioration or prevention of the subsequent dysmaturation (i.e., neurorestorative). Although there is overlap in this categorization, the distinction best facilitates the discussion that follows.

\section{Neuroprotective Interventions}

Neuroprotective interventions have focused on prevention of pre-OL injury or death. Many excellent recent reviews have addressed this issue and will not be discussed further. ${ }^{20,22,}$ 108, 171 The principal neuroprotective interventions and the likely mechanism(s) affected in the cascade to pre-OL death are shown in Table 3. Most of the mechanisms also are relevant to those examples of WMI that are accompanied by direct injury to axons and neurons as well as to 
pre-OLs. Of the interventions shown in Table 3 only erythropoietin (EPO) has been studied in detail in human premature infants and will be discussed here.

\section{Erythropoietin}

Because EPO has anti-excitotoxic, anti-oxidant, anti-inflammatory and anti-apoptotic effects, ${ }^{172}$ the agent is a prime candidate for prevention of pre-OL injury or death, the critical initial event in genesis of preterm WMI. EPO has been shown to prevent/mitigate WMI in a variety of experimental models. ${ }^{172-174}$ Although numerous studies of EPO in premature infants have been carried out, a recent meta-analysis of four randomized, controlled trials (RCT) comprising 1133 infants is especially useful. ${ }^{175}$ Prophylactic EPO administration reduced the incidence of Mental Developmental Index (MDI) scores of $<70$ (odds ratio 0.51 [0.31 - 0.81], $\mathrm{P}<$.005) at $18-24$ months. Because total numbers of infants $<28$ weeks' gestational age were not large enough to assess adequately the outcome in this critical group, more data are needed. A large multicenter RCT in the United States (PENUT Trial, NCT 01378273) is focused on this critical group, and results should be available this year.

A closer assessment of the key EPO trials suggests that the timing of EPO administration may be critical in the likelihood of benefit. Thus, in one series of studies utilizing early, relatively brief administrations of EPO (at $<3 \mathrm{hrs,} \mathrm{at} \mathrm{12-18} \mathrm{hours} \mathrm{and} \mathrm{at} \mathrm{36-42} \mathrm{hours} \mathrm{after} \mathrm{birth),}$ no significant differences in outcome at 2 years could be discerned ${ }^{176}$ (although MRI at term equivalent age showed decreased WMI and better white matter maturation in the EPO-treated infants). ${ }^{177,178}$ However, in a study utilizing EPO administration (as EPO or its higher glycosylated derivative darbepoietin) $3 \mathrm{x}$ /week through 35 weeks' postconceptual age, the treated infants had better cognitive outcomes and less neurodevelopmental impairment at 3.5 to 4 years of age, when compared to placebo-treated infants. ${ }^{179}$ Thus, the two different protocols re: 
timing of EPO administration suggest that with the early, relatively brief approach, EPO was functioning only as a neuroprotective agent, whereas with the more prolonged approach the agent may have functioned both as a neuroprotective and a neurorestorative intervention. Perhaps consistent with this notion, the largest study to date randomized 800 infants of $<32$ weeks' gestation to placebo or EPO administered intravenously within 72 hours of birth and then once every other day for 2 weeks. ${ }^{180}$. The rate of moderate/severe neurological disability at 18 months' corrected age was significantly lower in the EPO group (7.1\%) versus the placebo group $(18.8 \%)(\mathrm{OR}=0.22, \mathrm{CI} 0.19-0.55, \mathrm{P}<.001)$. Dosing in the aforementioned PENUT trial will be still more prolonged, i.e., initially, single doses intravenously, every other day, from day 1 to day 11, and subsequently, doses subcutaneously every other day until 32 weeks. The potential mechanisms for EPO's benefit concerning brain maturation, i.e., neurorestorative effects, will be discussed in the next section.

\section{Neurorestorative Interventions}

The emphasis of this review has been the evolution of the widespread dysmaturational events that follow the initial insult(s) and injury/death, especially to pre-OLs. These events develop over many weeks to months, and perhaps longer. This relatively protracted period raises the possibility of a long time-window for interventions potentially capable of ameliorating or preventing the dysmaturation. I will term these interventions neurorestorative. The principal such interventions, shown in Tables 4 and 5, are classified based on their study in experimental settings only (Table 4) or in clinical settings with human infants, principally preterm infants (Table 5).

\section{Experimental Studies}




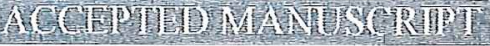

EGF, IGF-1. Both epidermal growth factor (EGF) and insulin-like growth factor (IGF1) have beneficial effects in experimental models of preterm WMI (Table 4). The agents appear to exhibit both neuroprotective and neurorestorative properties. In a mouse model of preterm WMI, Scafidi et al. showed that either selective overexpression of human EGF receptor in OL lineage cells or the intranasal administration of EGF immediately after injury led to decreased OL death, enhanced generation of new OLs from progenitor cells, and promoted functional recovery. ${ }^{181}$ The benign mode of administration of the EGF suggests potential clinical applicability.

IGF-1 has shown protective effects versus WMI both in neonatal animal models (hypoxia-ischemia, lipopolysaccharide-induced inflammation) and in cultured pre-OLs. ${ }^{182-186}$ The agent also showed restorative effects, i.e., rescue of pre-OLs and promotion of myelination. Two issues limit enthusiasm for IGF-1: first, the peptide must be administered intraventricularly, and second, its effects are dose-related, with lower doses effective but higher doses toxic.

Hyaluronidase Inhibitors. Pre-OL dysmaturation in chronic WMI appears related at least in considerable part to the astrocytic component of the diffuse gliosis characteristic of the lesion. Thus, Back and coworkers have shown that reactive astrocytes synthesize high molecular weight forms of hyaluronic acid, which are readily detectable in the human lesion. ${ }^{101,108}$ As described earlier, hyaluronic acid digestion products, generated from hyaluronidases in the disrupted extracellular matrix of WMI, lead to a block in pre-OL maturation. This block could be prevented by pharmacologic inhibition of hyaluronidase in vitro and in an animal model ${ }^{187}$ Whether use of a hyaluronidase inhibitor has value in preventing pre-OL dysmaturation in the human infant requires further study. 
Microglial or Astrocytic Phenotypic Manipulation. Abundant microglia are important components of the diffuse gliotic component of WMI (see earlier). These cells are principally in an activated, pro-inflammatory state (M1 phenotype). Their role in acute pre-OL injury/death likely relates to the generation of reactive oxygen and nitrogen species and secretion of injurious cytokines. ${ }^{20}$ However, a variety of studies, performed in in vitro and in vivo models, including adult human lesions with failure of OL differentiation and myelin development (e.g., multiple sclerosis), suggest involvement of activated microglia in the subsequent pre-OL dysmaturation in human preterm WMI. ${ }^{188-190}$ The data raise the possibility that interventions capable of converting microglia from a pro-inflammatory phenotype (M1) to an anti-inflammatory phenotype (M2) would have major potential as a neurorestorative therapy. Such immunomodulatory agents that cross the blood-brain barrier have been identified (e.g., minocycline, melatonin, minozac, etanercept) and are under study in human adult demyelinating diseases. ${ }^{16,189,} 191$ Their safety and efficacy in the premature infant for long-term use are not established. ${ }^{192}$

A recent relevant area of interest in regulation of microglial phenotype involves microRNAs ${ }^{191,}{ }^{193}$ These components are short non-coding RNAs (18-22 nucleotides) which are transcriptional regulators of gene expression. Several microRNAs have been shown to promote or inhibit inflammatory responses in microglia. One prominent microRNA of activated microglia is mir-155, which is elevated in microglia in multiple sclerosis lesions. When silenced in vivo by intracerebral injection of IL-17 in early stages of experimental allergic encephalomyelitis, the pathological and clinical effects of the demyelinating disease are blunted. ${ }^{193}$ Thus, the possibility of such systemic therapy seems real. Indeed, recent research shows that intravenous delivery of another microRNA (miR-124) that promotes polarization of microglia from an inflammatory (M1) to an anti-inflammatory (M2) phenotype via miR-124-enriched exosomes improves 
hippocampal neurogenesis and neurological function over four weeks after traumatic brain injury. ${ }^{194}$ (See also later discussion of exosomes.) Notably, because the anti-inflammatory phenotype of microglia (M2) is important in the facilitation of many brain developmental events as described earlier, these avenues of research suggest a major neurorestorative possibility for in vivo manipulation of microglia phenotype.

Similar considerations concerning glial manipulation from a "harmful" to developmentally "helpful" phenotype apply to the reactive astrocytes in the diffuse gliotic component. Their involvement in pre-OL injury and dysmaturation and the potential value of hyaluronidase inhibitors were discussed earlier. Prevention of the microglial induction of harmful, "neurotoxic" astrocytes (A1 phenotype) is an area of active current research. ${ }^{109,110}$ The valuable results would be inhibition of pre-OL death and preservation of the maturational effects of the developmentally beneficial astrocytic phenotype (A2). A variety of drugs and neutralizing antibodies (e.g., to $\mathrm{TNF} \alpha$, and $\mathrm{IL} \alpha$, from microglia) to prevent induction of harmful reactive astrocytes are under study in animal models and in adult human neurodegenerative disorders. ${ }^{109}$

Stem Cells. Experimental studies of stroke and related ischemic brain injuries in neonatal animals suggest that stem cell therapies may be effective for restoration, particularly of OLs. ${ }^{195-200}$ The major types of cells used thus far include neural, embryonic, mesenchymal, umbilical cord and induced pluripotent cells. In vitro manipulation of neural precursor cells prior to transplantation can enhance their capacity to undergo OL differentiation and axonal remyelination. ${ }^{201} \mathrm{~A}$ variety of routes of cell administration have been utilized, and intranasal administration may be the most efficient. Stem cells administered by this route appear to target the injury site after entering the brain via olfactory neural processes traversing the cribriform plate. ${ }^{202}$ Studies of rodent models of preterm brain injury have shown that the intranasal route of 
administration can be effective not only for mitigating injury to myelin but also for improving behavioral outcome. ${ }^{196,203}$

Of particular relevance to cerebral WMI and pre-OL dysmaturation/myelination failure in the premature infant is a recent study of such injury produced by hypoxia-ischemia in the 3-dayold rat. ${ }^{204}$ OL progenitor cells produced from embryonic stem cells were transplanted into the injured cerebrum. The transplanted cells survived, underwent differentiation, formed myelin sheaths and stimulated proliferation of endogenous neural stem cells. Supporting a neurorestorative effect was the demonstration of functional benefit after 6 weeks. It will be of particular interest if the results can be replicated after intranasal administration.

A relevant human study in this context involves the transplantation of human neural stem cells into the brains of four infants with connatal Pelizaeus-Merzbacher disease. ${ }^{205}$ After 1 year, evidence of myelin ensheathment of axons was obtained by diffusion tensor imaging. Direct extrapolation to the human preterm infant with WMI is difficult because of the mode of administration used. Nevertheless, the findings suggest promise for stem cell therapy as a neurorestorative therapy in such infants.

Exosomes. The precise neuroprotective factors released by stem cells are not known with certainty and may vary as a function of the injury. Notably, however, effects on pre-OL and myelin development and on behavioral outcome in a rodent model of preterm WMI was achieved with intravenous administration of extracellular vesicles, i.e., exosomes, derived from stem cells, in lieu of stem cells per se. ${ }^{206}$ (Exosomes are a type of extracellular vesicle and can carry membrane and cytosolic proteins, various types of RNA and lipids, and perhaps DNA). ${ }^{207}$ Similar benefit from the use of exosomes has been demonstrated in other animal models of brain injury. ${ }^{208-210}$ The great therapeutic potential of exosomes, isolated from blood, has been 
recognized only recently and the capacity to induce OL differentiation and myelination could serve a crucial neurorestorative function in the premature infant. Human studies will be of great interest.

Dendrimers. Dendrimers are unique nanoparticles synthesized for a variety of functions, including targeted delivery of therapeutic agents to brain. ${ }^{211,212}$ Their small size and tailorable surface functional groups make them valuable for this role. Drugs, and perhaps ultimately, microRNA's or silencing RNA's can be attached to the dendrimer. Several recent models of ischemia- or inflammation-induced neonatal or fetal brain injury have shown marked beneficial effects of dendrimer $-\mathrm{N}$-acetylcysteine conjugates. ${ }^{213-217} \mathrm{~N}$-Acetylcysteine is an anti-oxidant, and after intravenous administration of the conjugate, uptake into activated microglia, reactive astrocytes and differentiating OLs could be demonstrated. Sustained prevention of OL injury and improved myelination were shown. ${ }^{215}$ The principal cellular target appeared to be inflammatory microglia. Further studies will be of great interest.

\section{Clinical Studies}

A burgeoning clinical literature suggests the possibility that the dysmaturation of both pre-OLs and gray matter structures after premature brain injury can be counteracted to a considerable extent. These neurorestorative interventions include pharmacologic agents, i.e., EPO, and modifications of nutrition and other environmental factors (Table 5). Implementation of these interventions during the vulnerable neonatal period, when the remarkable array of developmental events described earlier are proceeding most rapidly, is of critical importance. However, the beneficial effects of these interventions likely continue beyond the neonatal period (see later). The mechanisms of the benefits and the specific maturational events affected are not yet entirely understood. Our current understanding of these interventions is discussed next. 
Erythropoietin. EPO was discussed earlier in relation to its neuroprotective effects.

Notably as discussed earlier, current data suggest that more prolonged exposure to EPO is more beneficial than only early and brief exposure, thus suggesting that EPO has neurorestorative as well as neuroprotective properties.

Experimental data suggest that neurorestorative effects of EPO involve particularly OL development, although promotion of angiogenesis and neurogenesis may also occur. ${ }^{118,172,218}$ In view of the likely importance of the failure of differentiation of pre-OLs in the genesis of axonal and neuronal dysmaturation, the decisive role of EPO in promoting pre-OL development after hypoxic-ischemic insults in experimental models is particularly relevant here. ${ }^{219-221}$ In vivo, EPO appears to be generated primarily from astrocytes, abundantly present in the diffuse gliotic component of WMI. However, the EPO receptor is upregulated in pre-OLs after hypoxicischemic insults, and if sufficient endogenous EPO is not present, the unoccupied receptor leads to a failure of differentiation. The provision of abundant exogenous EPO may explain the benefit of EPO therapy vis à vis pre-OL differentiation. An indirect effect of EPO on pre-OL and neuronal/axonal maturation may also relate to its action of decreasing microglial recruitment, the other key glial element in diffuse white matter gliosis, and thereby the deleterious effects of inflammation. ${ }^{222}$ Additionally, in an animal model, ${ }^{223}$ EPO also promotes cerebral cortical development after hypoxia-ischemia and associated subplate neuronal loss, again consistent with its multifaceted effects on cellular development in brain. Recall that in moderate to severe WMI in premature infants, subplate neuronal loss and impaired cortical development are important features (see earlier).

A major question re: EPO as a restorative therapy relates to the prolonged duration likely required. Reactive astrocytes and activated microglia are likely present for many months after the 
initial injury. More data are needed re: the safety of such prolonged treatment of an agent with multifaceted developmental effects.

Nutritional Factors. The importance of appropriate nutrition during the premature period for neurodevelopmental outcome and the deleterious effects of postnatal undernutrition are supported by a large corpus of clinical, epidemiological and experimental studies. ${ }^{224-238}$ In the context of this section the data raise the possibility that optimal nutrition, both in the neonatal period and the subsequent posthospitalization period, could be a restorative intervention in premature infants with WMI and the encephalopathy of prematurity. The high prevalence of impaired nutrition in premature infants is illustrated by observations that $50 \%$ of VLBW preterm infants had a discharge weight less than the 10th percentile for postmenstrual age, and $27 \%$ had a discharge weight less than the $3 \mathrm{rd}$ percentile. ${ }^{239,240}$.

The maturational events apparently vulnerable to nutritional disturbance in infancy have been elucidated at least preliminarily, by several MRI studies. ${ }^{155,160,241,242}$ Although results vary somewhat, impairments of cerebral cortical volumetric growth and microstructural differentiation, cerebral white matter microstructural maturation, and basal ganglia volumetric growth have been identified. Similar disturbances of brain maturation have been identified in infants born small for gestational age. ${ }^{164,166,167}$ Impaired nutrition in the postnatal period in premature infants has been determined either directly (e.g., energy and lipid intake) or indirectly (e.g., deficient enteral nutrition, prolonged parenteral nutrition). Whether some of the dysmaturational events in these settings are primary or secondary to pre-OL dysmaturation is unclear. Nevertheless, the implication is that optimal nutrition could be restorative in this context. 
The quality of the milk provided to the infant is another nutritional factor that appears important for neurological outcome and suggests a means for neurorestoration. Available data indicate particular value concerning neurodevelopmental outcome for fortified preterm versus term formula, for human milk versus formula, and for fortified human milk versus no fortification. $^{236,238,243-249}$

Breast-feeding is of particular value, and several volumetric and diffusion tensor MRI studies have shown better white maturation in such infants. ${ }^{235,236,244,247,248}$ Perhaps even more importantly, breast-feeding beyond the neonatal period appears to have long-lasting beneficial effects on cerebral white matter. Thus, a study of 133 (healthy) term-born infants either exclusively breast-fed for a mean of 413 days or exclusively formula fed or fed a mixture of formula and breast milk utilized advanced MRI measures at 10 months to 4 years of age to assess white matter development. ${ }^{247}$ The data show that early exclusive breast-feeding was associated with better development in relatively late maturing white matter regions, including frontal and temporal white matter, corticospinal tracts, and superior longitudinal and occipitofrontal fasciculi. Notably, several of these regions are important for specific higher-order cognitive domains, in which breast-fed infants have been shown to have improved performance. ${ }^{247,250}$ Thus, current data suggest that breast-feeding could have neurorestorative potential and that the principal initial effect may involve OL development and myelination.

Polyunsaturated fatty acids (PUFAs) are crucial for brain development and are particularly concentrated in phospholipids of neural membranes, especially in cerebral cortex and other gray matter structures. ${ }^{251-253}$ Most brain PUFAs are acquired in the last trimester of gestation and first two years of life, during rapid brain growth. ${ }^{254}$ Thus, the preterm infant does not receive this critical transplacental transfer of PUFAs. Notably, however, breast milk is an 
excellent source of PUFAs. Two recent studies utilizing advanced MRI techniques and determinations of PUFA levels in red blood cells noted positive correlations between PUFA levels and microstructural maturation of cerebral white matter and macrostructural (volumetric) development of cerebral cortex and basal ganglia/thalamus near-term equivalent age. ${ }^{254,255}$ Concerning the potential value of supplementation with PUFAs, although not all findings are consistent, favorable effects on visual function and cognitive function have been reported. ${ }^{238.256 \text {. }}$ ${ }^{257}$ Supplementation to the lactating mother who is breast-feeding has been most effective. Thus, the possibility of PUFA supplementation in this manner to the preterm infant, especially with the dysmaturational abnormalities of white and gray matter, is worthy of study as a neurorestorative intervention.

Iron is a critical nutrient for OL maturation. Iron deficiency can be an important contributing factor in causation of brain dysmaturation in premature infants, with particular involvement of OL maturation and subsequent myelination. Thus, iron supplementation as needed can be considered a potential neurorestorative intervention. Although the data are not entirely consistent, most studies show impairments of motor, cognitive and behavioral development in iron-deficient infants. ${ }^{258-262}$ Iron deficiency in the neonatal period is usually related to dietary deficiency; particularly in the context of breast-feeding and prematurity. ${ }^{263-265}$ Indeed, as many as $10 \%$ of infants in the first two years of life in the United States and $15 \%$ of breast-fed Canadian infants exhibit iron deficiency. Because premature birth deprives the infant of the primary period of fetal iron deposition, i.e., the third trimester of gestation, the risks are still higher in such infants. Supportive of an effect on myelin development in iron-deficient infants is the finding on studies of auditory and visual evoked potentials of prolonged latencies, without impairment of amplitudes. ${ }^{266-269}$ (The normal maturational decline in latencies relates to 
acquisition of myelin, whereas changes in amplitude relate more to neuronal development ${ }^{161}$ ). A recent study of delayed umbilical cord clamping (DCC) in full-term infants suggests a beneficial effect of iron on MRI-quantitated myelin at four months of age. ${ }^{270}$ Thus, infants followed after DCC had $48 \%$ higher serum ferritin levels and myelin content at 4 months of age, when compared to infants who had immediate cord clamping. Moreover, because infants with higher iron stores at 4 months of age have been shown to persist with higher stores later, the findings suggest that the positive effect on myelination may persist. ${ }^{271}$ More data are needed, but higher iron stores could represent an important neurorestorative goal in premature infants. The clinical findings re: iron and myelination are consistent with experimental studies showing the crucial role of iron in the processes of OL differentiation and myelination. ${ }^{263,265,272,273}$ Because iron also plays an important role in neurotransmitter metabolism, the neural effects of iron deficiency may extend beyond an impairment of OL development/myelination. ${ }^{274}$ Quantitative studies of myelination in living iron-deficient infants by advanced MRI measures would be of great interest.

Zinc is another critical nutrient for OL maturation. Zinc is critical for a variety of aspects of brain development, including OL development. ${ }^{275-279}$ The effect is mediated particularly by an OL-specific zinc finger protein (Zfp 488) that functions as a transcriptional co-regulator important for OL differentiation. ${ }^{280}$ Recent work has shown that zinc concentrations in developing OLs are relatively high during differentiation and decline after maturation is achieved. ${ }^{281}$ Moreover, altered zinc balance is involved in experimental models of ischemic and excitotoxic OL death. ${ }^{282-284}$ The clinical relevance of this work remains to be clarified fully, but it is notable that preterm infants are vulnerable to zinc deficiency because of high zinc requirements, diminished zinc stores (most zinc stores are acquired in the last trimester of 
gestation), and suboptimal zinc absorption. ${ }^{285-287}$ Moreover, zinc concentrations in human milk are highly variable, and current dietary guidelines for zinc intake for preterm infants are based on limited data. ${ }^{286,288}$ More data are needed in human preterm infants on OL maturation, myelination and neurological development, in relation to zinc status, and on ideal amounts of dietary zinc intake.

Experiential Factors. Experiential factors (Table 5) can play a major role in regulation of OL differentiation/myelination and neuronal/axonal development in human infants. ${ }^{18,19}$ Although emphasis is often placed on the deleterious effects of altered experience, especially in the neonatal period and particularly in the premature infant, the potential benefit of experiential factors as restorative therapies is important to consider. In this section, emphasis is placed on factors related to care in the neonatal period and later in infancy (Table 5).

A potential beneficial effect of modification of the neonatal auditory environment on cortical development and language outcome is suggested by recent clinical studies. The particular relevance of this work relates in part to the lay-out of neonatal intensive care units and associated attempts to minimize ambient noise. In part, because sound levels in many neonatal intensive care units, incubators and ventilators can exceed current recommendations of the American Academy of Pediatrics, ${ }^{289-293}$ many units have been designed to minimize such noise, often by maintaining infants in single rooms. Two recent studies suggest that this approach may have an adverse effect on language development and cerebral cortical development in premature infants. ${ }^{294,295}$ In a study of 136 preterm infants assigned to either open ward or single room bedspaces, infants cared for in single patient rooms had lower language scores at age 2 years, accompanied by abnormalities of cortical folding in the superior temporal area (after controlling for potential confounders) (Fig. 10). ${ }^{294}$ The difference in outcomes was attributed to differences 
in exposure to language in open areas vs. single rooms. In a subsequent study of the role of maternal involvement with the infant, outcomes were assessed for infants from both single patient rooms and open ward bedspaces while taking into account maternal involvement in the NICU care. ${ }^{295}$ Infants with high maternal involvement from both single patient and open ward bedspaces had higher cognitive and language scores at age 18 months than did infants with low maternal involvement. Notably, the effect size was greater for children from single rooms. This second study suggests that the level of language exposure depends on a variety of factors, including room type, but also other maternal characteristics that allow maternal verbal contact with the infant (e.g., availability of maternal leave, socio-economic status, time spent with the infant, a NICU culture that encourages verbal contact from parents). These latter issues also are important subsequent to the infant's discharge (see later),

The underlying pathophysiology of these effects of auditory experience on language development relates in part to the striking development of the auditory system during the premature period. Thus, connections between the cochlea and the brain stem are established by 24 to 25 weeks and connections to temporal lobe and auditory cortex by 30 to 31 weeks. ${ }^{296,297}$ Subsequently, cortical development occurs rapidly. Thus, it is biologically plausible that an important factor in the subsequent language impairment relates to a disruption of development of this key activity-dependent system. Consistent with this notion, functional connectivity MRI data show that disruption of brain networks detected at term equivalent age persists into childhood. ${ }^{298}$

The importance of the nature of the auditory input is shown by a recent study of the effects of different varieties of music exposure on cortical connectivity. A careful initial study utilizing fMRI showed that music exposure in preterm infants had at term equivalent age lasting learning effects on music processing - with an increased connectivity between primary auditory 
cortex and brain regions involved in several aspects of music processing (e.g., temporal and cingulate cortex, basal ganglia). ${ }^{299}$ Subsequent work will focus on the duration of such effects and effects on language processing. The initial findings suggest that details of the neonatal (and subsequent) auditory experience can have lasting beneficial effects on important areas of brain development.

Neonatal visual experience also appears to play an important role in the infant's brain development. Because WMI in the premature infant tends to be most severe in the parietooccipital region, ${ }^{127}$ central visual impairment is a common neurological sequelae. ${ }^{118}$ Notably, development of the axons of the geniculocalcarine tract, ensheathment of these axons by preOLs, early myelin formation of the tract and development of visual cortex are very active during the premature period and into infancy. ${ }^{18}$ Whether optimal visual experience in premature infants could capitalize on this actively developing system to counteract the deleterious central visual effects of WMI, i.e., have restorative properties, is important to consider. The data just reviewed re: auditory experiences are encouraging in this regard. Experimental studies in normal and preterm monkeys showed that premature visual stimulation resulted in increases in size and proportions of synapses in visual cortex, presumably by activity-dependent alterations in synaptogenesis, synaptic modification or synapse elimination. ${ }^{300}$ Visual deprivation had opposite and unfavorable effects. The somewhat limited data available in human infants suggest that, as in monkeys, visual experiential effects are important mediators of cortical development. Thus, visual experience of premature infants is associated with accentuation of the development of the visual evoked potential, a finding consistent with enhancement of axonal and dendritic development and synaptogenesis. ${ }^{301,302}$ More data are needed to address how visual experience 
could enhance development of the cerebral visual system and perhaps counteract the effects of dysmaturation described earlier.

Pain and stress in the neonatal period, common experiences for the preterm infant, have been shown to have adverse effects on neurodevelopmental, behavioral and cognitive outcomes. ${ }^{303-308}$ Abnormalities of brain development accompany these effects (see next). The findings suggest that reduction of pain and stress in these infants could serve as a neurorestorative intervention. (Table 5).

Several studies that quantitated pain and stress (either number of stressful events ${ }^{309}$ or number of painful (skinbreaks) procedures ${ }^{307,308,310,311}$ ) showed correlative disturbances in brain development involving cerebral cortex, thalamus, cerebral white matter and functional connectivity. Functional connectivity disturbance has been demonstrated as early as term equivalent age (Fig. 11). ${ }^{309}$ Although most abnormalities were detected at term equivalent age, thinning of cerebral cortex, especially in parietal and frontal areas, was identified at a mean age of 7.9 years. $^{311}$ Additional evidence concerning a relation of stress to cerebral white matter development emanates from a later randomized controlled clinical trial that evaluated the effectiveness of training parents in reducing stressful experiences in premature infants in the neonatal intensive care unit. ${ }^{312}$ At term equivalent age the infants of the mothers in the intervention group showed by advanced MRI significantly enhanced maturation and connectivity of cerebral white matter. These and related data caused the American Academy of Pediatrics to emphasize the need in neonatal intensive care facilities for "a pain-prevention program that includes strategies for minimizing the number of painful procedures performed". ${ }^{313}$ This evidence for a deleterious effect of pain and stress in the neonatal period suggests that interventions to reduce the responsible events could be neurorestorative. Moreover, the 
potential importance of stress as a deleterious factor beyond the neonatal period and prevention/amelioration of such stress as a neurorestorative intervention will be discussed later.

One approach to diminish neonatal stress has been the individualized developmental care approach pioneered by Als. ${ }^{314}$ The possible neurorestorative role of this approach was suggested by a randomized clinical trial of the Als care program, which showed at 9 months' corrected age, improved neurobehavioral function, quantitative EEG evidence of enhanced maturation, and diffusion-tensor MRI evidence of more advanced cerebral white matter fiber tract development. ${ }^{315}$ Benefits were still present at 8 years of age. ${ }^{316}$ Many elements of developmental care were identified, including patient positioning, light, sound, handling, approaches to feeding and inclusion of parents in care. ${ }^{317-319}$ The initial findings from this work regarding beneficial effects on brain maturation suggest the possibility that at least some of these approaches could lead to mitigation and recovery of the dysmaturational features of the encephalopathy of prematurity.

The mechanisms for the deleterious effects of stress on brain maturation, although not entirely understood in the human newborn and young infant, may involve brain microglia. ${ }^{320}$ Such stress mediators as glucocorticoids and catecholamines are known to lead to proinflammatory activation of microglia in experimental studies. In view of the key role of microglia in various aspects of brain maturation in early life and the substantial number of microglia in cerebral white matter in the human infant, especially in the diffuse gliosis of WMI (see earlier), such modulation of microglia toward a pro-inflammatory state could lead to dysmaturational events. Moreover, this modulation of microglia has been related to a potentiated response to subsequent stress, e.g., in infancy and beyond, with the exacerbation of 
dysmaturation and the promotion of cognitive and emotional disorders. Thus, in this context, elimination of stress would be a major neurorestorative intervention.

Parenting/educational/social factors are critical in the infant's experience, especially beyond the neonatal period, and suggest opportunities for neurorestorative intervention (Table 5). Many studies in recent years have shown that factors relating to parenting, parental education and socio-economic context beyond the neonatal period are critical determinants of ultimate neurodevelopmental outcome, especially relating to cognition, language and behavior. ${ }^{10,321-329}$ Initial research with MRI suggests that the anatomical substrate for impaired neurodevelopment in this setting involves changes in volumetric growth of cortex, deep nuclear structures and cerebral white matter. ${ }^{328,330}$ and in functional network maturation. ${ }^{328,331}$ The particular importance of early parenting behavior, particularly maternal affective involvement, parentchild synchrony, positive and responsive parenting, has been delineated and could represent a neurorestorative intervention. ${ }^{327-329}$

Although the deleterious experiential effects just described begin in the neonatal period, their persistence into infancy and early childhood raises the possibility that myelin development, a post-term event in human brain, could be especially affected. This possibility is supported by recent elegant studies of infants institutionally reared in orphanages under circumstances associated with lack of parenting and neglect, including social, emotional and linguistic deficiencies. Although disturbances in subsequent behavioral and cognitive functions in such infants are well-known, impairments in macrostructural and microstructural white matter development have been shown only recently. ${ }^{332-337}$ The potential to counteract this dysmaturation, i.e., a neurorestorative intervention, was shown by a large study of Romanian orphans randomly selected to remain in an institution or to be placed in supervised foster care at 
2 years of age. ${ }^{338}$ Studies by diffusion tensor MRI at 8 years of age showed significant associations between neglect in early life and impaired microstructural integrity of multiple white matter structures. Particular affection of radial diffusivity suggested impaired myelin ensheathment of axons. Early intervention (i.e., foster care) promoted more nearly normative white matter development among the previously neglected children. The particular link between environmental enrichment and white matter development is reminiscent of studies of specific skill development, e.g., musicians, which show a relation of enhanced skill to induced changes in white matter microstructure. Importantly, these changes are effected best during early sensitive periods, e.g., in childhood, and, moreover, enhance additional practiced-based changes in white matter microstructure and performance later in life. ${ }^{339}$ Notably, a large experimental literature supports maturational value for environmental enrichment in many animal models. ${ }^{328}$

Randomized intervention studies of older infants and young children in lower SES conditions, albeit less severely neglected than the aforementioned orphans, also show benefit for development of language, emotional regulation and cognitive skills. ${ }^{328,340,341}$ The anatomical substrate of these effects remain to be established. However, the demonstrated benefit raises important and complex societal issues.

\section{Conclusions}

This major section focused on interventions directed at pre-OL death and subsequent dysmaturation of white and gray matter structures. Interventions directed at protection vs. preOL death, termed "neuroprotective", discussed in detail elsewhere, were not emphasized. Of these, only EPO has been studied in human infants, and prolonged therapy seems preferable to brief courses. Interventions considered to be promising for amelioration or prevention of the subsequent dysmaturation, termed "neurorestorative", were emphasized. Promising pre-clinical 
data were reviewed. Clinical studies suggest value for EPO, optimal nutrition (concerning quality and source of milk, breastfeeding, polyunsaturated fatty acids, iron and zinc), and critical experiential interventions. The latter relate in the neonatal period to optimal auditory and visual experience and reduction of pain and stress. Importance for brain maturation also can be attributed to such interventions in infancy and early childhood as breastfeeding, carefully designed intervention programs, environmental enrichment and parental/educational/social factors.

\section{SUMMARY/CONCLUSIONS}

The principal focus of this review has been the dysmaturation of brain in infants born prematurely, especially very preterm. The dysmaturational details have been identified primarily by advanced MRI studies. The review has delineated (a) the dysmaturational features involving both white and gray matter structures; (b) the context of their occurrence, i.e., the remarkable array of developmental events in the human brain during the premature period; (c) the spectrum of the cerebral white matter injury that appears to initiate the dysmaturational events; (d) the likely mechanisms by which the white matter injury, particularly the mild forms now most prevalent in neonatal intensive care facilities, lead to the dysmaturation; and (e) the potential neurorestorative interventions suggested by a burgeoning amount of recent work, both clinical and experimental.

\section{References}




\section{References}

1. Liu L, Oza S, Hogan D, et al. Global, regional, and national causes of under-5 mortality in 200015: an updated systematic analysis with implications for the Sustainable Development Goals. Lancet 2016;388(10063):3027-3035.

2. Murphy SL, Mathews T, Martin JA, et al. Annual summary of vital statistics: 2013 - 2014. Pediatrics 2017;139(6):e20163239.

3. Ancel PY, Goffinet F, Kuhn P, et al. Survival and morbidity of preterm children born at 22 through 34 weeks' gestation in France in 2011: Results of the EPIPAGE-2 cohort study. JAMA Pediatr 2015:E1-E9.

4. Helenius K, Sjors G, Shah PS, et al. Survival in very preterm infants: An international comparison of 10 national neonatal networks. Pediatrics 2017;140(6):e20171264.

5. Boghossian NS, Geraci M, Edwards EM, et al. Morbidity and mortality in small for gestational age infants at 22 to 29 weeks' gestation. Pediatrics 2018;141(2):e20172533.

6. Kerstjens JM, de Winter AF, Bocca-Tjeertes IF, et al. Risk of developmental delay increases exponentially as gestational age of preterm infants decreases: a cohort study at age 4 years. Dev Med Child Neurol 2012;54(12):1096-1101.

7. Hirvonen $\mathrm{M}$, Ojala $\mathrm{R}$, Korhonen $\mathrm{P}$, et al. Cerebral palsy among children born moderately and late preterm. Pediatrics 2014;134(6):e1584-1593.

8. Peralta-Carcelen M, Carlo WA, Pappas A, et al. Behavioral problems and socioemotional competence at 18 to 22 months of extremely premature children. Pediatrics 2017;139(6):e20161043.

9. Cheong JLY, Anderson PJ, Burnett AC, et al. Changing neurodevelopment at 8 years in children born extremely preterm since the 1990s. Pediatrics 2017;139(6):e20164086.

10. Nguyen TN, Spencer-Smith M, Haebich KM, et al. Language trajectories of children born very preterm and full term from early to late childhood. J Pediatr 2018;202:86-91.

11. Amer R, Moddemann D, Seshia M, et al. Neurodevelopmental outcomes of infants born at $<29$ weeks of gestation admitted to Canadian Neonatal Intensive Care Units based on location of birth. J Pediatr 2018;196:31-37.

12. Broring $\mathrm{T}$, Oostrom $\mathrm{KJ}$, van Dijk-Lokkart EM, et al. Attention deficit hyperactivity disorder and autism spectrum disorder symptoms in school-age children born very preterm. Res Dev Disabil 2018;74:103-112.

13. Twilhaar ES, Wade RM, de Kieviet JF, et al. Cognitive outcomes of children born extremely or very preterm since the 1990 s and associated risk factors: A meta-analysis and meta-regression. JAMA Pediatr 2018;172(4):361-367.

14. Burnett $\mathrm{AC}$, Anderson PJ, Lee $\mathrm{KJ}$, et al. Trends in executive functioning in extremely preterm children across 3 birth eras. Pediatrics 2018;141(1):e20171958.

15. Spittle AJ, Cameron K, Doyle LW, et al. Motor impairment trends in extremely preterm children: 1991-2005. Pediatrics 2018;141(4).

16. Bolk J, Farooqi A, Hafstrom $M$, et al. Developmental coordination disorder and its association with developmental comorbidities at 6.5 years in apparently healthy children born extremely preterm. JAMA Pediatr 2018;172(8):765-774.

17. Volpe JJ. Brain injury in premature infants: a complex amalgam of destructive and developmental disturbances. Lancet Neurol 2009;8(4):110-124.

18. Kinney HC, Volpe JJ. Organizational events In: Volpe JJ, Inder TE, Darras BT, et al., eds. Volpe's Neurology of the Newborn. Chapter 7, 6th ed. Philadelphia, PA: Elsevier; 2018:145-175.

19. Kinney HC, Volpe JJ. Myelination events. In: Volpe JJ, Inder TE, Darras BT, et al., eds. Volpe's Neurology of the Newborn. Chapter 8, 6th ed. Philadelphia, PA: Elsevier; 2018:176-188. 
20. Volpe JJ, Kinney HC, Jensen FE, et al. The developing oligodendrocyte: key cellular target in brain injury in the premature infant. Int J Devl Neurosci 2011;29:423-440.

21. Back SA. Brain injury in the preterm infant: New horizons for pathogenesis and prevention. Pediatr Neurol 2015;53(3):185-192.

22. Back SA, Volpe JJ. Encephalopathy of Prematurity: Pathophysiology. In: Volpe JJ, Inder TE, Darras BT, et al., eds. Volpe's Neurology of the Newborn. Chapter 15, 6th ed. Philadelphia, PA: Elsevier; 2018:405-424.

23. Back SA, Luo NL, Borenstein NS, et al. Late oligodendrocyte progenitors coincide with the developmental window of vulnerability for human perinatal white matter injury. J Neurosci 2001;21(4):1302-1312.

24. Back SA, Luo NL, Borenstein NS, et al. Arrested oligodendrocyte lineage progression during human cerebral white matter development: Dissociation between the timing of progenitor differentiation and myelinogenesis. J Neuropathol Exp Neurol 2002;61:197-211.

25. Hardy R, Reynolds R. Neuron-oligodendroglial interactions during central nervous system development. J Neurosci Res 1993;36(2):121-126.

26. Barres BA, Raff MC. Axonal control of oligodendrocyte development. J Cell Biol 1999;147(6):1123-1128.

27. Yamazaki $Y$, Hozumi $Y$, Kaneko $K$, et al. Oligodendrocytes: facilitating axonal conduction by more than myelination. Neuroscientist 2010;16(1):11-18.

28. Kremer D, Aktas $\mathrm{O}$, Hartung HP, et al. The complex world of oligodendroglial differentiation inhibitors. Ann Neurol 2011;69(4):602-618.

29. Kramer-Albers EM, White R. From axon-glial signalling to myelination: the integrating role of oligodendroglial Fyn kinase. Cell Mol Life Sci 2011;68(12):2003-2012.

30. Lee $\mathrm{Y}$, Morrison BM, Li Y, et al. Oligodendroglia metabolically support axons and contribute to neurodegeneration. Nature 2012;487(7408):443-448.

31. Oluich L, Stratton JA, Lulu Xing Y, et al. Targeted ablation of oligodendrocytes induces axonal pathology independent of overt demyelination. J Neurosci 2012;32(24):8317-8330.

32. Berret $\mathrm{E}$, Barron $\mathrm{T}, \mathrm{Xu}$ J, et al. Oligodendroglial excitability mediated by glutamatergic inputs and Nav1.2 activation. Nat Commun 2017;8(1):557.

33. Jiang $C$, Yang $W$, Fan $Z$, et al. AATYK is a novel regulator of oligodendrocyte differentiation and myelination. Neurosci Bull 2018;34(3):527-533.

34. Santos AK, Vieira MS, Vasconcellos $R$, et al. Decoding cell signalling and regulation of oligodendrocyte differentiation. Semin Cell Dev Biol 2018:[Epub ahead of print].

35. Srivastava T, Diba P, Dean JM, et al. A TLR/AKT/Fox03 immune tolerance-like pathway disrupts the repair capacity of oligodendrocyte progenitors. J Clin Invest 2018;128(5):2025-2041.

36. Haynes RL, Borenstein NS, DeSilva TM, et al. Axonal development in the cerebral white matter of the human fetus and infant. J Comp Neurol 2005;484:156-167.

37. Kostovic I, Judas M. Correlation between the sequential ingrowth of afferents and transient patterns of cortical lamination in preterm infants. Anat Rec 2002;267:1-6.

38. Kostovic $I$, Judas $M$, Rados $M$, et al. Laminar organization of the human fetal cerebrum revealed by histochemical markers and magnetic resonance imaging. Cereb Cortex 2002;12(5):536-544.

39. Kostovic I, Jovanov-Milosevic N. The development of cerebral connections during the first 20-45 weeks' gestation. Semin Fetal Neonatal Med 2006;11:415-422.

40. Kostovic I, Judas M. Transient patterns of cortical lamination during prenatal life: do they have implications for treatment? Neurosci Biobehav Rev 2007;31(8):1157-1168.

41. Conel J. The Postnatal Development of the Human Cerebral Cortex. Cambridge: Harvard University Press; 1939. 
42. Mrzljak L, Uylings $\mathrm{H}$, Kostovic $\mathrm{I}$, et al. Prenatal development of neurons in the human prefrontal cortex: I.A. qualitative Golgi study. J Comp Neurol 1988;271:355-386.

43. Marin-Padilla M. Early ontogenesis of the human cerebral cortex. In: Peters A, Jones EG, eds. Cerebral Cortex. Vol 7. NY: Plenum Publishing Corp.; 1988:1-34.

44. Marin-Padilla M. Ontogenesis of the pyramidal cell of the mammalian neocortex and developmental cytoarchitectonics: A unifying theory. J Comp Neurol 1992;321:233-240.

45. Marin-Padilla M. Prenatal and early postnatal ontogenesis of the human motor cortex: A Golgi study. I. The sequential development of the cortical layers. Brain Res 1970;23(2):167-183.

46. Goodman CS, Shatz CJ. Developmental mechanisms that generate precise patterns of neuronal connectivity. Cell 1993;72:77-98.

47. Schlaggar BL, Fox K, Oleary DM. Postsynaptic control of plasticity in developing somatosensory cortex. Nature 1993;364:623-626.

48. Johnston MV. Neurotransmitters and vulnerability of the developing brain. Brain Dev 1995;17:301-306.

49. Flint AC, Liu XL, Kriegstein AR. Nonsynaptic glycine receptor activation during early neocortical development. Neuron 1998;20(1):43-53.

50. Bardoul M, Levallois $C$, Konig N. Functional AMPA/kainate receptors in human embryonic and foetal central nervous system. J Chem Neuroanat 1998;14:79-85.

51. Aizawa $\mathrm{H}, \mathrm{Hu}$ SC, Bobb K, et al. Dendrite development regulated by CREST, a calcium-regulated transcriptional activator. Science 2004;303:197-202.

52. Reiprich $P$, Kilb W, Luhmann HJ. Neonatal NMDA receptor blockade disturbs neuronal migration in rat somatosensory cortex in vivo. Cereb Cortex 2005;15:349-358.

53. Konur S, Ghosh A. Calcium signaling and the control of dendritic development. Neuron 2005;46:401-405.

54. Chen Y, Wang PY, Ghosh A. Regulation of cortical dendrite development by Rap1 signaling. Mol Cell Neurosci 2005;28:215-228.

55. Chen YC, Ghosh A. Regulation of dendritic development by neuronal activity. J Neurobiol 2005;64:4-10.

56. Yap EL, Greenberg ME. Activity-regulated transcription: bridging the gap between neural activity and behavior. Neuron 2018;100(2):330-348.

57. Sarnat HB, Philippart $M$, Flores-Sarnat $L$, et al. Timing in neural maturation: arrest, delay, precociousness, and temporal determination of malformations. Pediatr Neurol 2015;52(5):473486.

58. Sarnat HB, Flores-Sarnat L, Trevenen CL. Synaptophysin immunoreactivity in the human hippocampus and neocortex from 6 to 41 weeks of gestation. J Neuropathol Exp Neurol 2010;69(3):234-245.

59. Talos DM, Fishman RE, Park H, et al. Developmental regulation of alpha-amino-3-hydroxy-5methyl-4-isoxazole-propionic acid receptor subunit expression in forebrain and relationship to regional susceptibility to hypoxic/ischemic injury. I. Rodent cerebral white matter and cortex. J Comp Neurol 2006;497:42-60.

60. Talos DM, Follett PL, Folkerth RD, et al. Developmental regulation of alpha-amino-3-hydroxy-5methyl-4-isoxazole-propionic acid receptor subunit expression in forebrain and relationship to regional susceptibility to hypoxic/ischemic injury. II. Human cerebral white matter and cortex. J Comp Neurol 2006;497:61-77.

61. Bystron I, Blakemore C, Rakic P. Development of the human cerebral cortex: Boulder Committee revisited. Nat Rev Neurosci 2008;9(2):110-122.

62. Zecevic N, Chen YH, Filipovic R. Contributions of cortical subventricular zone to the development of the human cerebral cortex. J Comp Neurol 2005;491:109-122. 
63. Letinic $\mathrm{K}$, Zoncu R, Rakic $\mathrm{P}$. Origin of GABAergic neurons in the human neocortex. Nature 2002;417(6889):645-649.

64. Rakic P. Developmental and evolutionary adaptations of cortical radial glia. Cereb Cortex 2003;13(6):541-549.

65. Tan SS. Developmental neurobiology: cortical liars. Nature 2002;417(6889):605-606.

66. Xu G, Broadbelt KG, Haynes RL, et al. Late development of the GABAergic system in the human cerebral cortex and white matter. J Neuropathol Exp Neurol 2011;70(10):841-858.

67. Hamilton SP, Rome LH. Stimulation of in vitro myelin synthesis by microglia. Glia 1994;11(4):326335.

68. Rezaie P, Male D. Differentiation, ramification and distribution of microglia within the central nervous system examined. Neuroembryology 2002;1:29-43.

69. Rezaie $P$, Dean A, Male D, et al. Microglia in the cerebral wall of the human telencephalon at second trimester. Cereb Cortex 2005;15:938-949.

70. Schafer DP, Lehrman EK, Kautzman AG, et al. Microglia sculpt postnatal neural circuits in an activity and complement-dependent manner. Neuron 2012;74(4):691-705.

71. Squarzoni P, Oller G, Hoeffel G, et al. Microglia modulate wiring of the embryonic forebrain. Cell Rep 2014;8(5):1271-1279.

72. Reemst K, Noctor SC, Lucassen PJ, et al. The indispensable roles of microglia and astrocytes during brain development. Front Hum Neurosci 2016;10:1-28.

73. Hickman S, Izzy S, Sen P, et al. Microglia in neurodegeneration. Nat Neurosci 2018;21(10):13591369.

74. Guttenplan K, Blum J, Bennett M. A role for microglia in retinal development. J Neurosci 2018;38(43):9126-9128.

75. Hammond TR, Robinton D, Stevens B. Microglia and the brain: complementary partners in development and disease. Annu Rev Cell Dev Biol 2018;34:523-544.

76. Hammond TR, Dufort C, Dissing-Olesen L, et al. Single-cell RNA sequencing of microglia throughout the mouse lifespan and in the injured brain reveals complex cell-state changes. Immunity 2019;50:1-19.

77. Agresti C, D'Urso D, Levi G. Reversible inhibitory effects of interferon- $\gamma$ - and tumour necrosis factor- $\alpha$ on oligodendroglial lineage cell proliferation and differentiation in vitro. Eur J Neurosci 1996;8:1106-1116.

78. Andrews T, Zhang P, Bhat NR. TNF- $\alpha$ potentiates IFN $\gamma$-induced cell death in oligodendrocyte progenitors. J Neurosci Res 1998;54:574-583.

79. Xie $Z$, Wei M, Morgan TE, et al. Peroxynitrite mediates neurotoxicity of amyloid $\beta$-peptide 1-42and lipopolysaccharide-activated microglia. J Neurosci 2002;22:3484-3492.

80. Rivest S. Molecular insights on the cerebral innate immune system. Brain Behav Immun 2003;17:13-19.

81. Lehnardt $S$, Massillon $L$, Follett $P$, et al. Activation of innate immunity in the CNS triggers neurodegeneration through a Toll-like receptor 4-dependent pathway. PNAS (USA) 2003;100(14):8514-8519.

82. Buntinx $M$, Moreels $M$, Vandenabeele $F$, et al. Cytokine-induced cell death in human oligodendroglial cell lines: I. Synergistic effects of IFN-gamma and TNF-alpha on apoptosis. J Neurosci Res 2004;76:834-845.

83. Li J, Baud O, Vartanian T, et al. Peroxynitrite generated by inducible nitric oxide synthase and NADPH oxidase mediates microglial toxicity to oligodendrocytes. PNAS (USA) 2005;102(28):9936-9941.

84. Pang Y, Cai ZW, Rhodes PG. Effect of tumor necrosis factor-alpha on developing optic nerve oligodendrocytes in culture. J Neurosci Res 2005;80(2):226-234. 
85. Larouche A, Roy $\mathrm{M}$, Kadhim $\mathrm{H}$, et al. Neuronal injuries induced by perinatal hypoxic-ischemic insults are potentiated by prenatal exposure to lipopolysaccharide: animal model for perinatally acquired encephalopathy. Dev Neurosci 2005;27:134-142.

86. Monier A, Evrard $P$, Gressens $P$, et al. Distribution and differentiation of microglia in the human encephalon during the first two trimesters of gestation. J Comp Neurol 2006;499(4):565-582.

87. Billiards SS, Haynes RL, Folkerth RD, et al. Development of microglia in the cerebral white matter of the human fetus and infant. J Comp Neurol 2006;497(2):199-208.

88. Zhang $\mathrm{Y}$, Inder TE, Neil JJ, et al. Cortical structural abnormalities in very preterm children at 7years of age. Neuroimage 2015;109:469-479.

89. Smyser CD, Snyder AZ, Shimony JS, et al. Resting-state network complexity and magnitude are reduced in prematurely born infants. Cereb Cortex 2016;26(1):322-333.

90. Rajagopalan V, Scott JA, Liu M, et al. Complementary cortical gray and white matter developmental patterns in healthy, preterm neonates. Hum Brain Mapp 2017;38(9):4322-4336.

91. Batalle $\mathrm{D}$, Hughes $\mathrm{EJ}$, Zhang $\mathrm{H}$, et al. Early development of structural networks and the impact of prematurity on brain connectivity. Neuroimage 2017;149:379-392.

92. Neil JJ, Smyser CD. Recent advances in the use of MRI to assess early human cortical development. J Magn Reson 2018;293:56-69.

93. Smyser CD, Wheelock MD, Limbrick DD, Jr., et al. Neonatal brain injury and aberrant connectivity. Neuroimage 2019;185:609-623.

94. Banker BQ, Larroche JC. Periventricular leukomalacia of infancy. A form of neonatal anoxic encephalopathy. Arch Neurol 1962;7:386-410.

95. Gilles FH. Hypotensive brain stem necrosis. Selective symmetrical necrosis of tegmental neuronal aggregates following cardiac arrest. Arch Pathol 1969;88:32-41.

96. Armstrong D, Norman MG. Periventricular leucomalacia in neonates. Complications and sequelae. Arch Dis Child 1974;49(5):367-375.

97. Shuman RM, Selednik L. Periventricular leukomalacia. A one-year autopsy study. Arch Neurol 1980;37(4):231-235.

98. Okoshi Y, Itoh M, Takashima S. Characteristic neuropathology and plasticity in periventricular leukomalacia. Pediatr Neurol 2001;25:221-226.

99. Kinney HC, Armstrong DC. Perinatal neuropathology. In: Graham DI, Lantos PL, eds. Greenfield's Neuropathology. 7th ed. London: Arnold; 2002:543-551.

100. Pierson CR, Folkerth RD, Billards SS, et al. Gray matter injury associated with periventricular leukomalacia in the premature infant. Acta Neuropathol 2007;114:619-631.

101. Buser JR, Maire J, Riddle A, et al. Arrested preoligodendrocyte maturation contributes to myelination failure in premature infants. Ann Neurol 2012;71(1):93-109.

102. Volpe JJ. Confusions in nomenclature: "periventricular leukomalacia" and "white matter injury" identical, distinct, or overlapping? Pediatr Neurol 2017;73:3-6.

103. Haynes RL, Folkerth RD, Keefe R, et al. Nitrosative and oxidative injury to premyelinating oligodendrocytes is accompanied by microglial activation in periventricular leukomalacia in the human premature infant. J Neuropathol Exp Neurol 2003;62:441-450.

104. Back SA, Luo NL, Mallinson RA, et al. Selective vulnerability of preterm white matter to oxidative damage defined by F(2)-isoprostanes. Ann Neurol 2005;58:108-120.

105. Billiards SS, Haynes RL, Folkerth RD, et al. Myelin abnormalities without oligodendrocyte loss in periventricular leukomalacia. Brain Pathol 2008;18(2):153-163.

106. Emery B, Agalliu D, Cahoy JD, et al. Myelin gene regulatory factor is a critical transcriptional regulator required for CNS myelination. Cell 2009;138(1):172-185.

107. Fancy SP, Baranzini SE, Zhao C, et al. Dysregulation of the Wnt pathway inhibits timely myelination and remyelination in the mammalian CNS. Genes Dev 2009;23(13):1571-1585. 
108. Back SA. White matter injury in the preterm infant: pathology and mechanisms. Acta Neuropathol 2017;134(3):331-349.

109. Liddelow SA, Barres BA. Reactive Astrocytes: Production, Function, and Therapeutic Potential. Immunity 2017;46(6):957-967.

110. Liddelow SA, Guttenplan KA, Clarke LE, et al. Neurotoxic reactive astrocytes are induced by activated microglia. Nature 2017;541(7638):481-487.

111. Cekanaviciute E, Buckwalter MS. Astrocytes: integrative regulators of neuroinflammation in stroke and other neurological diseases. Neurotherapeutics 2016;13(4):685-701.

112. Cargill R, Kohama SG, Struve J, et al. Astrocytes in aged nonhuman primate brain gray matter synthesize excess hyaluronan. Neurobiol Aging 2012;33(4):830 e813-824.

113. Sloane JA, Batt $C, M a Y$, et al. Hyaluronan blocks oligodendrocyte progenitor maturation and remyelination through TLR2. PNAS (USA) 2010;107(25):11555-11560.

114. Folkerth RD, Keefe RJ, Haynes RL, et al. Interferon-gamma expression in periventricular leukomalacia in the human brain. Brain Pathol 2004;14(3):265-274.

115. Deguchi K, Oguchi K, Takashima S. Characteristic neuropathology of leukomalacia in extremely low birth weight infants. Pediatr Neurol 1997;16:296-300.

116. Donat CK, Scott G, Gentleman SM, et al. Microglial activation in traumatic brain injury. Front Aging Neurosci 2017;9:208.

117. Kwon SH, Vasung L, Ment LR, et al. The role of neuroimaging in predicting neurodevelopmental outcomes of preterm neonates. Clin Perinatol 2014;41(1):257-283.

118. Neil JJ, Volpe JJ. Encephalopathy of prematurity: Clinical-neurological features, diagnosis, imaging, prognosis, therapy. In: Volpe JJ, Inder TE, du Plessis AJ, et al., eds. Volpe's Neurology of the Newborn. Chapter 16, 6th ed. Philadelphia, PA: Elsevier; 2018:425-457.

119. Chau V, Synnes A, Grunau RE, et al. Abnormal brain maturation in preterm neonates associated with adverse neurodevelopmental outcomes. Neurology 2013;81(24):2082-2089.

120. Kersbergen KJ, Benders MJ, Groenendaal F, et al. Different patterns of punctate white matter lesions in serially scanned preterm infants. PLoS One 2014;9(10):e108904.

121. Guo T, Duerden EG, Adams E, et al. Quantitative assessment of white matter injury in preterm neonates: Association with outcomes. Neurology 2017;88(7):614-622.

122. Tusor N, Benders MJ, Counsell SJ, et al. Punctate white matter lesions associated with altered brain development and adverse motor outcome in preterm tnfants. Sci Rep 2017;7(1):13250.

123. Woodward LJ, Anderson PJ, Austin NC, et al. Neonatal MRI to predict neurodevelopmental outcomes in preterm infants. N Engl J Med 2006;355:685-694.

124. Hintz SR, Barnes PD, Bulas D, et al. Neuroimaging and neurodevelopmental outcome in extremely preterm infants. Pediatrics 2015;135(1):e32-42.

125. Linsell L, Johnson $S$, Wolke $D$, et al. Cognitive trajectories from infancy to early adulthood following birt $\mathrm{h}$ before 26 weeks of gestation: a prospective, population-based cohort study. Arch Dis Child 2018;103:363-370.

126. Anderson PJ, Treyvaud K, Neil JJ, et al. Associations of newborn brain magnetic resonance imaging with long-term neurodevelopmental impairments in very preterm children. J Pediatr 2017;187:58-65 e51.

127. Kinney HC, Volpe JJ. Encephalopathy of Prematurity: Neuropathology. In: Volpe JJ, Inder TE, Darras BT, et al., eds. Volpe's Neurology of the Newborn. Chapter 14, 6th ed. Philadelphia, PA: Elsevier; 2018:389-404.

128. Haynes RL, Billiards SS, Borenstein NS, et al. Diffuse axonal injury in periventricular leukomalacia as determined by apoptotic marker fractin. Pediatr Res 2008;63:656-661.

129. Tekkok SB, Goldberg MP. AMPA/kainate receptor activation mediates hypoxic oligodendrocyte death and axonal injury in cerebral white matter. J Neurosci 2001;21(12):4237-4248. 
130. Wakita $\mathrm{H}$, Tomimoto $\mathrm{H}$, Akiguchi I, et al. Axonal damage and demyelination in the white matter after chronic cerebral hypoperfusion in the rat. Brain Res 2002;924:63-70.

131. Sizonenko SV, Sirimanne E, Mayall Y, et al. Selective cortical alteration after hypoxic-ischemic injury in the very immature rat brain. Pediatr Res 2003;54:263-269.

132. McCarran WJ, Goldberg MP. White matter axon vulnerability to AMPA/kainate receptormediated ischemic injury is developmentally regulated. J Neurosci 2007;27(15):4220-4229.

133. Alix JJ, Zammit C, Riddle A, et al. Central axons preparing to myelinate are highly sensitivity to ischemic injury. Ann Neurol 2012;72(6):936-951.

134. Ligam P, Haynes RL, Folkerth RD, et al. Thalamic damage in periventricular leukomalacia: Novel pathologic observations relevant to cognitive deficits in survivors of prematurity. Pediatr Res 2009;65:524-529.

135. Northington FJ, Ferriero DM, Flock DL, et al. Delayed neurodegeneration in neonatal rat thalamus after hypoxia-ischemia is apoptosis. J Neurosci 2001;21(6):1931-1938.

136. Northington FJ, Ferriero DM, Martin L. Neurodegeneration in the thalamus following neonatal hypoxia-ischemia is programmed cell death. Dev Neurosci 2001;23(3):186-191.

137. McConnell SK, Ghosh A, Shatz CJ. Subplate neurons pioneer the first axon pathway from the cerebral cortex. Science 1989;245(4921):978-982.

138. Ghosh A, Antonini A, McConnell SK, et al. Requirement for subplate neurons in the formation of thalamocortical connections. Nature 1990;347(6289):179-181.

139. Ghosh A, Shatz CJ. Involvement of subplate neurons in the formation of ocular dominance columns. Science 1992;255(5050):1441-1443.

140. Ghosh A, Shatz CJ. A role for subplate neurons in the patterning of connections from thalamus to neocortex. Development 1993;117:1031-1047.

141. Volpe JJ. Subplate neurons - missing link in brain injury of the premature infant? Pediatrics 1996;97:112-113.

142. Kanold PO, Kara P, Reid RC, et al. Role of subplate neurons in functional maturation of visual cortical columns. Science 2003;301:521-525.

143. Kanold PO. Transient microcircuits formed by subplate neurons and their role in functional development of thalamocortical connections. NeuroReport 2004;15:2149-2153.

144. Bystron I, Molnar Z, Otellin V, et al. Tangential networks of precocious neurons and early axonal outgrowth in the embryonic human forebrain. J Neurosci 2005;25:2781-2792.

145. McQuillen PS, Sheldon RA, Shatz CJ, et al. Selective vulnerability of subplate neurons after early neonatal hypoxia-ischemia. J Neurosci 2003;23(8):3308-3315.

146. Robinson S, Li Q, Dechant A, et al. Neonatal loss of gamma-aminobutyric acid pathway expression after human perinatal brain injury. J Neurosurg 2006;104(6 Suppl):396-408.

147. Kinney HC, Haynes RL, Xu G, et al. Neuron deficit in the white matter and subplate in periventricular leukomalacia. Ann Neurol 2012;71(3):397-406.

148. Boardman JP, Counsell SJ, Rueckert D, et al. Abnormal deep grey matter development following preterm birth detected using deformation based morphometry. Neurolmage 2006;32:70-78.

149. Anjari $M$, Srinivasan $L$, Allsop JM, et al. Diffusion tensor imaging with tract-based spatial statistics reveals local white matter abnormalities in preterm infants. Neurolmage 2007;35:1021-1027.

150. Dubois J, Benders $M$, Cachia $A$, et al. Mapping the early cortical folding process in the preterm newborn brain. Cereb Cortex 2008;18(6):1444-1454.

151. Boardman JP, Craven C, Valappil S, et al. A common neonatal image phenotype predicts adverse neurodevelopmental outcome in children born preterm. Neuroimage 2010;52(2):409-414.

152. Ball G, Boardman JP, Rueckert D, et al. The effect of preterm birth on thalamic and cortical development. Cereb Cortex 2012;22(5):1016-1024. 
153. Ball G, Boardman JP, Aljabar P, et al. The influence of preterm birth on the developing thalamocortical connectome. Cortex 2013;49(6):1711-1721.

154. Ball G, Aljabar $P$, Nongena $P$, et al. Multimodal image analysis of clinical influences on preterm brain development. Ann Neurol 2017;82(2):233-246.

155. Barnett ML, Tusor N, Ball G, et al. Exploring the multiple-hit hypothesis of preterm white matter damage using diffusion MRI. Neuroimage Clin 2018;17:596-606.

156. Ajayi-Obe M, Saeed N, Cowan FM, et al. Reduced development of cerebral cortex in extremely preterm infants. Lancet 2000;356:1162-1163.

157. Ball G, Pazderova $L$, Chew A, et al. Thalamocortical connectivity predicts cognition in children born preterm. Cereb Cortex 2015.

158. Wimberger DM, Roberts TP, Barkovich AJ, et al. Identification of "premyelination" by diffusionweighted MRI. J Comput Assist Tomogr 1995;19:28-33.

159. Tolcos $\mathrm{M}$, Bateman $\mathrm{E}, \mathrm{O}^{\prime}$ Dowd $\mathrm{R}$, et al. Intrauterine growth restriction affects the maturation of myelin. Exp Neurol 2011;232(1):53-65.

160. Vinall J, Grunau RE, Brant R, et al. Slower postnatal growth is associated with delayed cerebral cortical maturation in preterm newborns. Sci Transl Med 2013;5(168):168ra168.

161. Neil JJ, Volpe JJ. Specialized neurological studies. In: Volpe JJ, Inder TE, Darras BT, et al., eds. Volpe's Neurology of the Newborn. Chapter 10, 6th ed. Philadelphia, PA: Elsevier; 2018:222-254.

162. Tolsa CB, Zimine S, Warfield SK, et al. Early alteration of structural and functional brain development in premature infants born with intrauterine growth restriction. Pediatr Res 2004;56:132-138.

163. Dubois J, Benders M, Borradori-Tolsa C, et al. Primary cortical folding in the human newborn: an early marker of later functional development. Brain 2008;131(Pt 8):2028-2041.

164. Lodygensky GA, Seghier ML, Warfield SK, et al. Intrauterine growth restriction affects the preterm infant's hippocampus. Pediatr Res 2008;63(4):438-443.

165. Padilla N, Falcon C, Sanz-Cortes $M$, et al. Differential effects of intrauterine growth restriction on brain structure and development in preterm infants: a magnetic resonance imaging study. Brain Res 2011;1382:98-108.

166. Xydis V, Drougia A, Giapros V, et al. Brain growth in preterm infants is affected by the degree of growth restriction at birth. J Matern Fetal Neonatal Med 2013;26(7):673-679.

167. Eikenes L, Martinussen MP, Lund LK, et al. Being born small for gestational age reduces white matter integrity in adulthood: a prospective cohort study. Pediatr Res 2012;72(6):649-654.

168. Dean JM, McClendon E, Hansen K, et al. Prenatal cerebral ischemia disrupts MRI-defined cortical microstructure through disturbances in neuronal arborization. Sci Transl Med 2013;5(168):168ra167.

169. McClendon $\mathrm{E}$, Chen $\mathrm{K}$, Gong $\mathrm{X}$, et al. Prenatal cerebral ischemia triggers dysmaturation of caudate projection neurons. Ann Neurol 2014;75(4):508-524.

170. McClendon E, Shaver DC, Degener-O'Brien K, et al. Transient hypoxemia chronically disrupts maturation of preterm fetal ovine subplate neuron arborization and activitym. J Neurosci 2017;37(49):11912-11929.

171. Inder TE, Volpe JJ. Pathophysiology: General Principles. In: Volpe JJ, Inder TE, Darras BT, et al., eds. Volpe's Neurology of the Newborn. Chapter 13, 6th ed. Philadelphia, PA: Elsevier; 2018:325388.

172. Rangarajan V, Juul SE. Erythropoietin: emerging role of erythropoietin in neonatal neuroprotection. Pediatr Neurol 2014;51(4):481-488.

173. Rees S, Hale N, De Matteo R, et al. Erythropoietin is neuroprotective in a preterm ovine model of endotoxin-induced brain injury. J Neuropathol Exp Neurol 2010;69(3):306-319. 
174. Mazur M, Miller RH, Robinson S. Postnatal erythropoietin treatment mitigates neural cell loss after systemic prenatal hypoxic-ischemic injury. J Neurosurg Pediatr 2010;6(3):206-221.

175. Fischer HS, Reibel NJ, Buhrer C, et al. Prophylactic early erythropoietin for neuroprotection in preterm infants: A meta-analysis. Pediatrics 2017;139(5):e20164317.

176. Natalucci G, Latal B, Koller B, et al. Effect of early prophylactic high-dose recombinant human erythropoietin in very preterm enfants on neurodevelopmental outcome at 2 years: a randomized clinical trial. JAMA 2016;315(19):2079-2085.

177. Leuchter $\mathrm{RH}$, Gui L, Poncet $\mathrm{A}$, et al. Association between early administration of high-dose erythropoietin in preterm infants and brain MRI abnormality at term-equivalent age. JAMA 2014;312(8):817-824.

178. O'Gorman RL, Bucher HU, Held U, et al. Tract-based spatial statistics to assess the neuroprotective effect of early erythropoietin on white matter development in preterm infants. Brain 2015;138(Pt 2):388-397.

179. Ohls RK, Cannon DC, Phillips J, et al. Preschool assessment of preterm infants treated with darbepoetin and erythropoietin. Pediatrics 2016;137(3):1-9.

180. Song J, Sun H, Xu F, et al. Recombinant human erythropoietin improves neurological outcomes in very preterm infants. Ann Neurol 2016;80:24-34.

181. Scafidi J, Hammond TR, Scafidi S, et al. Intranasal epidermal growth factor treatment rescues neonatal brain injury. Nature 2014;506(7487):230-234.

182. Cao Y, Gunn AJ, Bennet L, et al. Insulin-like growth factor (IGF)-1 suppresses oligodendrocyte caspase- 3 activation and increases glial proliferation after ischemia in near-term fetal sheep. $J$ Cereb Blood Flow Metab 2003;23:739-747.

183. Brywe KG, Mallard C, Gustavsson M, et al. IGF-I neuroprotection in the immature brain after hypoxia-ischemia, involvement of Akt and GSK3beta? Eur J Neurosci 2005;21(6):1489-1502.

184. Wood TL, Loladze V, Altieri S, et al. Delayed IGF-1 administration rescues oligodendrocyte progenitors from glutamate-induced cell death and hypoxic-ischemic brain damage. Dev Neurosci 2007;29(4-5):302-310.

185. Zhong J, Zhao L, Du Y, et al. Delayed IGF-1 treatment reduced long-term hypoxia-ischemiainduced brain damage and improved behavior recovery of immature rats. Neurol Res 2009;31(5):483-489.

186. Pang $\mathrm{Y}$, Zheng $\mathrm{B}$, Campbell LR, et al. IGF-1 can either protect against or increase LPS-induced damage in the developing rat brain. Pediatr Res 2010;67(6):579-584.

187. Preston $\mathrm{M}$, Gong $\mathrm{X}$, Su $\mathrm{W}$, et al. Digestion products of the $\mathrm{PH} 20$ hyaluronidase inhibit remyelination. Ann Neurol 2013;73(2):266-280.

188. Favrais $G$, van de Looij $Y$, Fleiss $B$, et al. Systemic inflammation disrupts the developmental program of the white matter. Ann Neurol 2011;70:550-565.

189. Miron VE, Boyd A, Zhao JW, et al. M2 microglia and macrophages drive oligodendrocyte differentiation during CNS remyelination. Nat Neurosci 2013;16(9):1211-1218.

190. Krishnan ML, Van Steenwinckel J, Schang AL, et al. Integrative genomics of microglia implicates DLG4 (PSD95) in the white matter development of preterm infants. Nat Commun 2017;8(1):428.

191. Michell-Robinson MA, Touil H, Healy LM, et al. Roles of microglia in brain development, tissue maintenance and repair. Brain 2015;138(Pt 5):1138-1159.

192. Biran V, Phan Duy A, Decobert $F$, et al. Is melatonin ready to be used in preterm infants as a neuroprotectant? Dev Med Child Neurol 2014;56(8):717-723.

193. Ksiazek-Winiarek D, Szpakowski P, Turniak M, et al. IL-17 exerts anti-apoptotic affect via miR155-5p downregulation in experimental autoimmune encephalomyelitis. J Mol Neurosci 2017;63(3-4):320-332. 
194. Yang $\mathrm{Y}, \mathrm{Ye} \mathrm{Y}$, Kong $\mathrm{C}$, et al. MiR-124 Enriched exosomes promoted the $\mathrm{M} 2$ polarization of microglia and enhanced hippocampus neurogenesis after traumatic brain injury by inhibiting TLR4 pathway. Neurochem Res 2019.

195. Titomanlio L, Kavelaars A, Dalous J, et al. Stem cell therapy for neonatal brain injury: perspectives and challenges. Ann Neurol 2011;70(5):698-712.

196. van Velthoven CT, Sheldon RA, Kavelaars A, et al. Mesenchymal stem cell transplantation attenuates brain injury after neonatal stroke. Stroke 2013;44(5):1426-1432.

197. Fleiss B, Guillot PV, Titomanlio L, et al. Stem cell therapy for neonatal brain injury. Clin Perinatol 2014;41(1):133-148.

198. van Velthoven CT, Gonzalez F, Vexler ZS, et al. Stem cells for neonatal stroke- the future is here. Front Cell Neurosci 2014;8(207):1-3.

199. Wei ZZ, Gu X, Ferdinand A, et al. Intranasal delivery of bone marrow mesenchymal stem cells improved neurovascular regeneration and rescued neuropsychiatric deficits after neonatal stroke in rats. Cell Transplant 2015;24(3):391-402.

200. Li J, Yawno T, Sutherland A, et al. Term vs. preterm cord blood cells for the prevention of preterm brain injury. Pediatr Res 2017;82(6):1030-1038.

201. Nagoshi N, Khazaei M, Ahlfors JE, et al. Human spinal oligodendrogenic neural progenitor cells promote functional recovery after spinal cord injury by axonal remyelination and tissue sparing. Stem Cells Transl Med 2018;7:806-818.

202. Li YH, Feng L, Zhang GX, et al. Intranasal delivery of stem cells as therapy for central nervous system disease. Exp Mol Pathol 2015;98(2):145-151.

203. Oppliger B, Joerger-Messerli M, Mueller M, et al. Intranasal delivery of umbilical cord-derived mesenchymal stem cells preserves myelination in perinatal brain damage. Stem Cells Dev 2016;25(16):1234-1242.

204. Chen LX, Ma SM, Zhang P, et al. Neuroprotective effects of oligodendrocyte progenitor cell transplantation in premature rat brain following hypoxic-ischemic injury. PLoS One 2015;10(3):e0115997.

205. Osorio MJ, Rowitch DH, Tesar P, et al. Concise review: Stem cell-based treatment of PelizaeusMerzbacher disease. Stem Cells 2017;35(2):311-315.

206. Drommelschmidt K, Serdar M, Bendix I, et al. Mesenchymal stem cell-derived extracellular vesicles ameliorate inflammation-induced preterm brain injury. Brain Behav Immun 2017;60:220-232.

207. Holm MM, Kaiser JR, Schwab ME. Extracellular vesicles: Multimodal envoys in neural maintenance and repair. Trends in Neurosci 2018;41(8):360-372.

208. Otero-Ortega L, Gomez de Frutos MC, Laso-Garcia F, et al. Exosomes promote restoration after an experimental animal model of intracerebral hemorrhage. J Cereb Blood Flow Metab 2018;38(5):767-779.

209. Williams A, Dennahy IS, Bhatti UF, et al. Mesenchymal stem cell-derived exosomes provide neuroprotection and improve long-term neurologic outcomes in a swine model of traumatic brain injury and hemorrhagic shock. J Neurotrauma 2018:[Epub ahead of press].

210. Zhao $L$, Jiang $X$, Shi J, et al. Exosomes derived from bone marrow mesenchymal stem cells overexpressing microRNA-25 protect spinal cords against transient ischemia. J Thorac Cardiovasc Surg 2018: Epub ahead of print.

211. Menjoge AR, Kannan RM, Tomalia DA. Dendrimer-based drug and imaging conjugates: design considerations for nanomedical applications. Drug Discov Today 2010;15(5-6):171-185.

212. Kannan RM, Nance E, Kannan S, et al. Emerging concepts in dendrimer-based nanomedicine: from design principles to clinical applications. J Intern Med 2014;276(6):579-617. 
213. Kannan S, Dai H, Navath RS, et al. Dendrimer-based postnatal therapy for neuroinflammation and cerebral palsy in a rabbit model. Sci Transl Med 2012;4(130):130ra146.

214. Kim ID, Shin JH, Kim SW, et al. Intranasal delivery of HMGB1 siRNA confers target gene knockdown and robust neuroprotection in the postischemic brain. Mol Ther 2012;20(4):829839.

215. Nance $E$, Porambo $M$, Zhang $F$, et al. Systemic dendrimer-drug treatment of ischemia-induced neonatal white matter injury. J Control Release 2015;214:112-120.

216. Nemeth $\mathrm{CL}$, Drummond GT, Mishra MK, et al. Uptake of dendrimer-drug by different cell types in the hippocampus after hypoxic-ischemic insult in neonatal mice: Effects of injury, microglial activation and hypothermia. Nanomedicine 2017;13(7):2359-2369.

217. Lei J, Rosenzweig JM, Mishra MK, et al. Maternal dendrimer-based therapy for inflammationinduced preterm birth and perinatal brain injury. Sci Rep 2017;7(1):6106.

218. Weisglas-Kuperus N, Heersema DJ, Baerts W, et al. Visual functions in relation with neonatal cerebral ultrasound, neurology and cognitive development in very-low-birthweight children. Neuropediatrics 1993;24:149-154.

219. Iwai M, Stetler RA, Xing J, et al. Enhanced oligodendrogenesis and recovery of neurological function by erythropoietin after neonatal hypoxic/ischemic brain injury. Stroke 2010;41(5):10321037.

220. Kato $\mathrm{S}$, Aoyama $\mathrm{M}$, Kakita $\mathrm{H}$, et al. Endogenous erythropoietin from astrocyte protects the oligodendrocyte precursor cell against hypoxic and reoxygenation injury. $J$ Neurosci Res 2011;89(10):1566-1574.

221. Jantzie LL, Miller RH, Robinson S. Erythropoietin signaling promotes oligodendrocyte development following prenatal systemic hypoxic-ischemic brain injury. Pediatr Res 2013;74(6):658-667.

222. Liu W, Shen Y, Plane JM, et al. Neuroprotective potential of erythropoietin and its derivative carbamylated erythropoietin in periventricular leukomalacia. Exp Neurol 2011;230(2):227-239.

223. Jantzie LL, Corbett CJ, Firl DJ, et al. Postnatal erythropoietin mitigates impaired cerebral cortical development following subplate loss from prenatal hypoxia-ischemia. Cereb Cortex 2015;25(9):2683-2695.

224. Hayakawa M, Okumura A, Hayakawa $F$, et al. Nutritional state and growth and functional maturation of the brain in extremely low birth weight infants. Pediatrics 2003;111:991-995.

225. Latal-Hajnal B, Von Siebenthal K, Kovari H, et al. Postnatal growth in VLBW infants: significant association with neurodevelopmental outcome. J Pediatr 2003;143:163-170.

226. Ehrenkranz RA, Dusick AM, Vohr BR, et al. Growth in the neonatal intensive care unit influences neurodevelopmental and growth outcomes of extremely low birth weight infants. Pediatrics 2006;117(4):1253-1261.

227. Lira PIC, Eickmann SE, Lima MC, et al. Early head growth: relation with IQ at 8 years and determinants in term infants of low and appropriate birthweight. Dev Med Child Neurol 2010;52:40-46.

228. Belfort MB, Rifas-Shiman SL, Sullivan T, et al. Infant growth before and after term: effects on neurodevelopment in preterm infants. Pediatrics 2011;128(4):e899-906.

229. Neubauer V, Griesmaier E, Pehbock-Walser N, et al. Poor postnatal head growth in very preterm infants is associated with impaired neurodevelopment outcome. Acta Paediatr 2013;102(9):883888.

230. Belfort MB, Gillman MW, Buka SL, et al. Preterm infant linear growth and adiposity gain: tradeoffs for later weight status and intelligence quotient. J Pediatr 2013;163(6):1564-1569 e1562.

231. Pyhala $R$, Hovi $P$, Lahti $M$, et al. Very low birth weight, infant growth, and autism-spectrum traits in adulthood. Pediatrics 2014;134(6):1075-1083. 
232. Leppanen $M$, Lapinleimu $\mathrm{H}$, Lind $\mathrm{A}$, et al. Antenatal and postnatal growth and 5 -year cognitive outcome in very preterm infants. Pediatrics 2014;133(1):63-70.

233. Frondas-Chauty A, Simon L, Branger B, et al. Early growth and neurodevelopmental outcome in very preterm infants: impact of gender. Arch Dis Child Fetal Neonatal Ed 2014;99(5):F366-372.

234. Sammallahti S, Pyhala $R$, Lahti $M$, et al. Infant growth after preterm birth and neurocognitive abilities in young adulthood. J Pediatr 2014;165(6):1109-1115.

235. Elitt CM, Rosenberg PA. The challenge of understanding cerebral white matter injury in the premature infant. Neuroscience 2014;276:216-238.

236. Belfort MB, Anderson PJ, Nowak VA, et al. Breast milk feeding, brain development, and neurocognitive outcomes: A 7-year longitudinal study in infants born at less than 30 weeks' gestation. J Pediatr 2016;177:133-139 e131.

237. Cusick SE, Georgieff MK. The role of nutrition in brain development: the golden opportunity of the "first 1000 days". J Pediatr 2016;175:16-21.

238. Belfort MB, Ehrenkranz RA. Neurodevelopmental outcomes and nutritional strategies in very low birth weight infants. Semin Fetal Neonatal Med 2017;22(1):42-48.

239. Horbar JD, Ehrenkranz RA, Badger GJ, et al. Weight growth velocity and postnatal growth failure in infants 501 to 1500 grams: 2000-2013. Pediatrics 2015;136(1):e84-92.

240. Griffin IJ, Tancredi DJ, Bertino E, et al. Postnatal growth failure in very low birthweight infants born between 2005 and 2012. Arch Dis Child Fetal Neonatal Ed 2016;101(1):F50-55.

241. Schneider J, Fischer Fumeaux CJ, Duerden EG, et al. Nutrient intake in the first two weeks of life and brain growth in preterm neonates. Pediatrics 2018;141(3):e20172169.

242. Coviello C, Keunen K, Kersbergen KJ, et al. Effects of early nutrition and growth on brain volumes, white matter microstructure, and neurodevelopmental outcome in preterm newborns. Pediatr Res 2018;83(1-1):102-110.

243. Tanaka K, Kon N, Ohkawa N, et al. Does breastfeeding in the neonatal period influence the cognitive function of very-low-birth-weight infants at 5 years of age? Brain Dev 2009;31(4):288293.

244. Isaacs EB, FischI BR, Quinn BT, et al. Impact of breast milk on intelligence quotient, brain size, and white matter development. Pediatr Res 2010;67(4):357-362.

245. Quigley MA, Hockley C, Carson C, et al. Breastfeeding is associated with improved child cognitive development: a population-based cohort study. J Pediatr 2011;160(1):25-32.

246. Bernard JY, De Agostini M, Forhan A, et al. Breastfeeding duration and cognitive development at 2 and 3 years of age in the EDEN mother-child cohort. J Pediatr 2013;163(1):36-42 e31.

247. Deoni SC, Dean DC, 3rd, Piryatinsky I, et al. Breastfeeding and early white matter development: A cross-sectional study. Neuroimage 2013;82:77-86.

248. Ou X, Andres A, Cleves MA, et al. Sex-specific association between infant diet and white matter integrity in 8-y-old children. Pediatr Res 2014;76(6):535-543.

249. Gibertoni D, Corvaglia L, Vandini S, et al. Positive effect of human milk feeding during NICU hospitalization on 24 month neurodevelopment of very low birth weight infants: An italian cohort study. PLoS One 2015;10(1):e0116552.

250. Grossmann T, Johnson MH. The development of the social brain in human infancy. Eur J Neurosci 2007;25(4):909-919.

251. Innis SM. Perinatal biochemistry and physiology of long-chain polyunsaturated fatty acids. J Pediatr 2003;143:S1-58.

252. Xiao Y, Huang Y, Chen ZY. Distribution, depletion and recovery of docosahexaenoic acid are region-specific in the rat brain. Br J Nutr 2005;94:544-550.

253. Innis SM. Fatty acids and early human development. Early Hum Dev 2007;83:761-766. 
254. Kamino D, Studholme C, Liu M, et al. Postnatal polyunsaturated fatty acids associated with larger preterm brain tissue volumes and better outcomes. Pediatr Res 2018;83(1-1):93-101.

255. Tam EW, Chau V, Barkovich AJ, et al. Early postnatal docosahexaenoic acid levels and improved preterm brain development. Pediatr Res 2016;79(5):723-730.

256. Makrides M, Gibson RA, McPhee AJ, et al. Neurodevelopmental outcomes of preterm infants fed high-dose docosahexaenoic acid: a randomized controlled trial. JAMA 2009;301(2):175-182.

257. Jensen CL, Voigt RG, Llorente AM, et al. Effects of early maternal docosahexaenoic acid intake on neuropsychological status and visual acuity at five years of age of breast-fed term infants. J Pediatr 2010;157(6):900-905.

258. Friel JK, Aziz K, Andrews WL, et al. A double-masked randomized control trial of iron supplementation in early infancy in healthy term breast-fed inifants. J Pediatr 2003;143:582586.

259. Lozoff B, De Andraca I, Castillo M, et al. Behavioral and developmental effects of preventing iron-deficiency anemia in health full-term infants. Pediarics 2003;112:846-854.

260. Kon N, Tanaka K, Sekigawa M, et al. Association between iron status and neurodevelopmental outcomes among VLBW infants. Brain Dev 2010;32(10):849-854.

261. Berglund SK, Westrup B, Hagglof B, et al. Effects of iron supplementation of LBW infants on cognition and behavior at 3 years. Pediatrics 2013;131(1):47-55.

262. Berglund SK, Chmielewska A, Starnberg J, et al. Effects of iron supplementation of low-birthweight infants on cognition and behavior at 7 years: a randomized controlled trial. Pediatr Res 2018;83(1-1):111-118.

263. Yager JY, Hartfield DS. Neurologic manifestations of iron deficiency in childhood. Pediatr Neurol 2002;27:85-92.

264. Gordon N. Iron deficiency and the intellect. Brain \& Development 2003;25:3-8.

265. Georgieff MK, Innis SM. Controversial nutrients that potentially affect preterm neurodevelopment: essential fatty acids and iron. Pediatr Res 2005;57:99R-103R.

266. Roncagliolo $M$, Garrido $M$, Walter $T$, et al. Evidence of altered central nervous system development in infants with iron deficiency anemia at $6 \mathrm{mo}$ : delayed maturation of auditory brainstem responses. Am J Clin Nutr 1998;68(3):683-690.

267. Sarici SU, Serdar MA, Dundaroz MR, et al. Brainstem auditory-evoked potentials in irondeficiency anemia. Pediatr Neurol 2001;24(3):205-208.

268. Algarin $C$, Peirano $P$, Garrido $M$, et al. Iron deficiency anemia in infancy: long-lasting effects on auditory andvisual system functioning. Pediatr Res 2003;53:217-223.

269. Amin $S B$, Orlando $M$, Wang $H$. Latent iron deficiency in utero is associated with abnormal auditory neural myelination in $>/=35$ weeks gestational age infants. J Pediatr 2013;163(5):12671271.

270. Mercer JS, Erickson-Owens DA, Deoni SCL, et al. Effects of delayed cord clamping on 4-month ferritin levels, brain myelin content, and neurodevelopment: A randomized controlled trial. J Pediatr 2018;203:266-272.

271. Rao R, Bora R. Timing of umbilical cord clamping and infant brain development. J Pediatr 2018;203:8-10.

272. Connor JR, Benkovic SA. Iron regulation in the brain: histochemical, biochemical, and molecular considerations. Ann Neurol 1992;32 Suppl:S51-61.

273. de Vellis J, Carpenter E. Development. In: Siegel GJ, Albers RW, Brady ST, et al., eds. Basic Neurochemistry, Molecular, Cellular, and Medical Aspects. 7 ed. London: Elsevier; 2006:437-458.

274. Rao R, Tkac I, Unger EL, et al. Iron supplementation dose for perinatal iron deficiency differentially alters the neurochemistry of the frontal cortex and hippocampus in adult rats. Pediatr Res 2013;73(1):31-37. 
275. Frederickson CJ, Koh JY, Bush Al. The neurobiology of zinc in health and disease. Nat Rev Neurosci 2005;6(6):449-462.

276. Li Y, Maret W. Transient fluctuations of intracellular zinc ions in cell proliferation. Exp Cell Res 2009;315(14):2463-2470.

277. Fukada T, Yamasaki S, Nishida K, et al. Zinc homeostasis and signaling in health and diseases: Zinc signaling. J Biol Inorg Chem 2011;16(7):1123-1134.

278. Maret W. Zinc in cellular regulation: The nature and significance of "zinc signals". Int J Mol Sci 2017;18(11).

279. Kuspert M, Wegner M. SomethiNG 2 talk about-Transcriptional regulation in embryonic and adult oligodendrocyte precursors. Brain Res 2016;1638(Pt B):167-182.

280. Wang SZ, Dulin J, Wu H, et al. An oligodendrocyte-specific zinc-finger transcription regulator cooperates with Olig2 to promote oligodendrocyte differentiation. Development 2006;133(17):3389-3398.

281. Bourassa D, Elitt CM, McCallum AM, et al. Chromis-1, a ratiometric fluorescent probe optimized for two-photon microscopy reveals dynamic changes in labile $\mathrm{Zn}$ (II) in differentiating oligodendrocytes. ACS Sens 2018;3(2):458-467.

282. Zhang $Y$, Aizenman $E$, DeFranco DB, et al. Intracellular zinc release, 12-lipoxygenase activation and MAPK dependent neuronal and oligodendroglial death. Mol Med 2007;13(7-8):350-355.

283. Domercq $M$, Mato S, Soria FN, et al. Zn2+-induced ERK activation mediates PARP-1-dependent ischemic-reoxygenation damage to oligodendrocytes. Glia 2013;61(3):383-393.

284. Mato S, Sanchez-Gomez MV, Bernal-Chico A, et al. Cytosolic zinc accumulation contributes to excitotoxic oligodendroglial death. Glia 2013;61(5):750-764.

285. Krebs NF, Miller LV, Hambidge KM. Zinc deficiency in infants and children: a review of its complex and synergistic interactions. Paediatr Int Child Health 2014;34(4):279-288.

286. Terrin G, Berni Canani R, Di Chiara M, et al. Zinc in early life: A key element in the fetus and preterm neonate. Nutrients 2015;7(12):10427-10446.

287. Ackland ML, Michalczyk AA. Zinc and infant nutrition. Arch Biochem Biophys 2016;611:51-57.

288. Griffin IJ, Domellof M, Bhatia J, et al. Zinc and copper requirements in preterm infants: an examination of the current literature. Early Hum Dev 2013;89 Suppl 2:S29-34.

289. American Academy of Pediatrics COEH. Noise: a hazard for the fetus and newborn. American Academy of Pediatrics. Committee on Environmental Health. Pediatrics 1997;100(4):724-727.

290. Etzel RA, Balk SJ, Bearer CF, et al. Noise: A hazard for the fetus and newborn. Pediatrics 1997;100:724-727.

291. Roizen NJ. Nongenetic causes of hearing loss. Ment Retard Dev Disabil Res Rev 2003;9:120-127.

292. Zimmerman E, Lahav A. Ototoxicity in preterm infants: effects of genetics, aminoglycosides, and loud environmental noise. J Perinatol 2013;33(1):3-8.

293. Kazemizadeh Gol MA, Black A, Sidman J. Bone conduction noise exposure via ventilators in the neonatal intensive care unit. Laryngoscope 2015;125:2388-2392.

294. Pineda RG, Neil J, Dierker D, et al. Alterations in brain structure and neurodevelopmental outcome in preterm infants hospitalized in different neonatal intensive care unit environments. J Pediatr 2014;164(1):52-60

295. Lester BM, Salisbury AL, Hawes K, et al. 18-month follow-up of infants cared for in a singlefamily room neonatal intensive care unit. J Pediatr 2016;177:84-89.

296. Weitzman L, Graziani L, Duhamel L. Maturation and topography of the auditory evoked response of the prematurely born infant. Electroencephalogr Clin Neurophysiol 1967;23(1):82-83.

297. Starr A, Amlie RN, Martin WH, et al. Development of auditory function in newborn infants revealed by auditory brainstem potentials. Pediatrics 1977;60(6):831-839. 
298. Kwon SH, Scheinost D, Vohr B, et al. Functional magnetic resonance connectivity studies in infants born preterm: suggestions of proximate and long-lasting changes in language organization. Dev Med Child Neurol 2016;58 Suppl 4:28-34.

299. Lordier L, Loukas S, Grouiller F, et al. Music processing in preterm and full-term newborns: A psychophysiological interaction (PPI) approach in neonatal fMRI. Neuroimage 2019;185:857864.

300. Bourgeois JP, Jastreboff PJ, Rakic P. Synaptogenesis in visual cortex of normal and preterm monkeys: evidence for intrinsic regulation of synaptic overproduction. PNAS (USA) 1989;86(11):4297-4301.

301. Tsuneishi S, Casaer P. Effects of preterm extrauterine visual experience on the development of the human visual system: a flash VEP study. Dev Med Child Neurol 2000;42:663-668.

302. Schwindt E, Giordano V, Rona Z, et al. The impact of extrauterine life on visual maturation in extremely preterm born infants. Pediatr Res 2018;84(3):403-410.

303. Whitfield MF, Grunau RE. Behavior, pain perception, and the extremely low-birth weight survivor. Clin Perinatol 2000;27(2):363-379.

304. Grunau R. Early pain in preterm infants. A model of long-term effects. Clin Perinatol 2002;29(3):373-394, vii-viii.

305. Anand KJ, Aranda JV, Berde CB, et al. Analgesia and anesthesia for neonates: study design and ethical issues. Clin Ther 2005;27(6):814-843.

306. Doesburg SM, Chau CM, Cheung TP, et al. Neonatal pain-related stress, functional cortical activity and visual-perceptual abilities in school-age children born at extremely low gestational age. Pain 2013;154(10):1946-1952.

307. Duerden EG, Grunau RE, Guo T, et al. Early procedural pain is associated with regionally-specific alterations in thalamic development in preterm neonates. J Neurosci 2018;38(4):878-886.

308. Schneider J, Duerden EG, Guo T, et al. Procedural pain and oral glucose in preterm neonates: brain development and sex-specific effects. Pain 2018;159(3):515-525.

309. Smith GC, Gutovich J, Smyser C, et al. Neonatal intensive care unit stress is associated with brain development in preterm infants. Ann Neurol 2011;70(4):541-549.

310. Brummelte S, Grunau RE, Chau V, et al. Procedural pain and brain development in premature newborns. Ann Neurol 2012;71(3):385-396.

311. Ranger $M$, Chau CM, Garg A, et al. Neonatal pain-related stress predicts cortical thickness at age 7 years in children born very preterm. PLoS One 2013;8(10):e76702.

312. Milgrom J, Newnham C, Anderson PJ, et al. Early sensitivity training for parents of preterm infants: impact on the developing brain. Pediatr Res 2010;67(3):330-335.

313. Committee on Fetus and Newborn and Section on Anesthesiology and Pain Medicine. Prevention and management of procedural pain in the neonate: an update. Pediatrics 2016;137(2):e20154271.

314. Als H, Lawhon G, Brown E. Individualized behavioral and environmental care for very low birth weight preterm infants at high risk for bronchopulmonary dysplasia: neonatal intensive care unit and developmental outcome. Pediatrics 1986;78:1123-1132.

315. Als H, Duffy FH, McAnulty GB, et al. Early experience alters brain function and structure. Pediatrics 2004;113:846-857.

316. McAnulty GB, Duffy FH, Butler SC, et al. Effects of the newborn individualized developmental care and assessment program (NIDCAP) at age 8 years: preliminary data. Clin Pediatr (Phila) 2010;49(3):258-270.

317. Symington A, Pinelli J. Developmental care for promoting development and preventing morbidity in preterm infants. Cochrane Database Syst Rev 2006(2):CD001814. 
318. Lubbe W, Van der Walt CS, Klopper HC. Integrative literature review defining evidence-based neurodevelopmental supportive care of the preterm infant. J Perinat Neonatal Nurs 2012;26(3):251-259.

319. Pineda R, Guth $R$, Herring $A$, et al. Enhancing sensory experiences for very preterm infants in the NICU: an integrative review. J Perinatol 2017;37(4):323-332.

320. Wolf SA, Boddeke HW, Kettenmann H. Microglia in physiology and disease. Annu Rev Physiol 2017;79:619-643.

321. Gibbs BG, Forste R. Breastfeeding, parenting, and early cognitive development. J Pediatr 2014;164(3):487-493.

322. Brown HK, Speechley KN, Macnab J, et al. Mild prematurity, proximal social processes, and development. Pediatrics 2014;134(3):e814-824.

323. Hair NL, Hanson JL, Wolfe BL, et al. Association of child poverty, brain development, and academic achievement. JAMA Pediatr 2015;169(9):822-829.

324. Doyle LW, Cheong JL, Burnett A, et al. Biological and social influences on outcomes of extremepreterm/low-birth weight adolescents. Pediatrics 2015;136(6):e1513-e1520.

325. Linsell L, Malouf R, Morris J, et al. Prognostic factors for poor cognitive development in children born very preterm or with very low birth weight: A systematic review. JAMA Pediatr 2015;169(12):1162-1172.

326. Parker MG, Rybin DV, Heeren TC, et al. Postdischarge feeding interactions and neurodevelopmental outcome at 1-year corrected gestational age. J Pediatr 2016;174:104-110.

327. Treyvaud K, Doyle LW, Lee KJ, et al. Parenting behavior at 2 years predicts school-age performance at 7 years in very preterm children. J Child Psychol Psychiatr 2016;57(7):814-821.

328. Leijser LM, Siddiqi A, Miller SP. Imaging evidence of the effect of socio-economic status on brain structure and development. Semin Pediatr Neurol 2018;27:26-34.

329. Lean RE, Paul RA, Smyser TA, et al. Social adversity and cognitive, language, and motor development of very preterm children from 2 to 5 years of age. J Pediatr 2018;203:177-184 e171.

330. Betancourt LM, Avants B, Farah MJ, et al. Effect of socioeconomic status (SES) disparity on neural development in female African-American infants at age 1 month. Dev Sci 2016;19(6):947956.

331. Gao W, Alcauter S, Elton A, et al. Functional network development during the first year: relative sequence and socioeconomic correlations. Cereb Cortex 2015;25(9):2919-2928.

332. Eluvathingal TJ, Chugani HT, Behen ME, et al. Abnormal brain connectivity in children after early severe socioemotional deprivation: a diffusion tensor imaging study. Pediatrics 2006;117(6):2093-2100.

333. Behen ME, Muzik O, Saporta AS, et al. Abnormal fronto-striatal connectivity in children with histories of early deprivation: A diffusion tensor imaging study. Brain Imaging Behav 2009;3(3):292-297.

334. Govindan RM, Behen ME, Helder E, et al. Altered water diffusivity in cortical association tracts in children with early deprivation identified with Tract-Based Spatial Statistics (TBSS). Cereb Cortex 2010;20(3):561-569.

335. Sheridan MA, Fox NA, Zeanah $\mathrm{CH}$, et al. Variation in neural development as a result of exposure to institutionalization early in childhood. PNAS (USA) 2012;109(32):12927-12932.

336. Hanson JL, Adluru N, Chung MK, et al. Early neglect is associated with alterations in white matter integrity and cognitive functioning. Child Dev 2013;84(5):1566-1578.

337. Kumar A, Behen ME, Singsoonsud $P$, et al. Microstructural abnormalities in language and limbic pathways in orphanage-reared children: a diffusion tensor imaging study. J Child Neurol 2014;29(3):318-325. 
338. Bick J, Zhu T, Stamoulis C, et al. Effect of early institutionalization and foster care on long-term white matter development: A randomized clinical trial. JAMA Pediatr 2015:E1-E9.

339. Steele CJ, Zatorre RJ. Practice makes plasticity. Nat Neurosci 2018;21(12):1645-1646.

340. Heckman J, Pinto R, Savelyev P. Understanding the mechanisms through which an influential early childhood program boosted adult outcomes. Am Econ Rev 2013;103(6):2052-2086.

341. Campbell F, Conti G, Heckman JJ, et al. Early childhood investments substantially boost adult health. Science 2014;343(6178):1478-1485. 
